\title{
Development of low drying shrinkage foamed concrete and hygro-mechanical finite element model for prefabricated building fasçade applications
}

\author{
Kai Tai Wan ${ }^{\mathrm{a}, *}$, Honggang Zhu ${ }^{\mathrm{c}}$, Terry Y.P. Yuen ${ }^{\mathrm{b}}$, Binmeng Chen ${ }^{\mathrm{c}}$, \\ Chuanlin $\mathrm{Hu}^{\mathrm{c}}$, Christopher K.Y. Leung ${ }^{\mathrm{d}}$, Jun Shang Kuangd \\ ${ }^{a}$ Department of Mechanical, Aerospace and Civil Engineering, Brunel University London, \\ $U K$ \\ ${ }^{b}$ Department of Civil Engineering, National Chiao Tung University, Taiwan \\ ${ }^{c}$ Nano and Advanced Materials Institute Limited, Hong Kong \\ ${ }^{d}$ Department of Civil and Environmental Engineering, The Hong Kong University of \\ Science and Technology, Hong Kong
}

\begin{abstract}
Prefabricated lightweight concrete building fasçade can improve the energy efficiency of buildings and reduce the carbon emission of transportation. However, it is essential to maintain the dimensional stability of the full scale element. The drying shrinkage of lightweight foamed concrete was investigated in this study. The hypothesis of using the drying shrinkage of normal weight concrete to approximate that of lightweight foamed concrete of dry density about $1,500 \mathrm{~kg} / \mathrm{m}^{3}$ counterpart was verified. Three different strategies of reducing drying shrinkage were studied. The drying shrinkage of common ingredients of ordinary Portland cement (OPC) and ground granulated blast-furnace slag (GGBS) was commonly up to 2,000-3,000 $\mu \varepsilon$. The use of magnesium expansive agent with different calcination conditions could not reduce the drying shrinkage. The use of calcium sulfoaluminiate
\end{abstract}

\footnotetext{
*Email: KaiTai.Wan@brunel.ac.uk
} 
(CSA) cement with OPC and GGBS could significantly reduce the drying shrinkage within $1,000 \mu \varepsilon$ in standard testing environment. The formulation developed in laboratory was scaled up in a concrete production plant for prefabricated concrete elements. A lightweight full scale panel (the wet density was about $1,700 \mathrm{~kg} / \mathrm{m}^{3}$ ) was fabricated. The drying shrinkage of the developed formulation with CSA cement was only $161 \mu \varepsilon$ in the field test. A hygro-mechanical model was developed to model the diffusion, shrinkage and plastic strain evolution. The incremental stress-strain constitutive relationship of the hygro-mechanical model was derived for incorporating it into general finite element routine. The model parameters were calibrated by the drying shrinkage measurements in this study. The calibrated model demonstrated the cracking potential of three typical reinforced concrete panels of three different formulations studied in this study.

Keywords:

foamed concrete; drying shrinkage; calcium sulfoaluminate cement; magnesium expansion agent; hygro-mechanical model; finite element

\section{1. Introduction}

2 Residential buildings in densely populated regions are commonly made of 3 reinforced concrete. About 40-50\% of energy consumed in buildings is spent 4 on space heating and cooling. Heat is wasted through the building envelope.

${ }_{5}$ Even inside the building, heat may be transferred from one compartment 6 to another unintentionally. The problem is exacerbated when floor heating 7 system is used [57]. To improve the energy efficiency of building, it is desirable

8 to minimise the heat transfer through the building envelope and partition of 
compartments by reducing the thermal conductivity, which is defined by the product of thermal diffusivity, specific heat capacity and density. As a general rule, the lower the density is, the lower the thermal conductivity for the same type of material. The density of concrete or cementitious material can be reduced by using lightweight aggregate [3, 35], incorporating significant volume of air void (aerated concrete) $[28,59]$ or the combination of both $[54,51,39,47]$. The air void of aerated concrete can be incorporated by gas-forming chemicals (aluminium powder, hydrogen peroxide, potassium permanganate or calcium carbide) or preformed foam by mixing compressed air, pressurised water and foaming agent (detergents, resin soap, saponin or hydrolysed proteins) [52, 53, 43]. Alternatively, if the targeted dry density is higher than $1,200 \mathrm{~kg} / \mathrm{m}^{3}$, it is possible to mix foaming agent in the wet mix to incorporate sufficient air void in the matrix by the shear stress induced during mixing. However, the dosage of foaming agent to achieve the targeted density depends on the type of foaming agent, rheology of the mix, mixer type and mixing time [17].

There are satisfactory solutions of internal non-structural partition walls such as autoclaved aerated concrete blocks and lightweight gypsum blocks. However, they are not suitable for the external walls and floor slabs which are usually structural elements. An alternative is to reduce the density of normal concrete of the building envelope and floor slab. Nevertheless, it is more difficult to control the quality of cast-in-situ lightweight concrete because it is sensitive to temperature, member geometry and casting procedure. Instead, the quality assurance can be improved by prefabrication in factory. Moreover, it is more environmental friendly and the productivity is higher to adopt 
prefabricated reinforced concrete elements compared to traditional cast-insitu method [16, 31, 14].

The authors used OpenLCA 1.6.3 with the European reference Life Cycle Database (ELCD) to estimate the Global Warming Potential (GWP) of the transportation of twelve $2.9 \mathrm{~m} \times 2 \mathrm{~m} \times 0.06 \mathrm{~m}$ prefabricated reinforced concrete walls with different specific gravity for $200 \mathrm{~km}$ from the factory to construction site by a typical lorry. The GWP is reduced by $44 \%$ when the density of the material is two-third of normal reinforced concrete while it is $75 \%$ less when the density is reduced by half (the density is assumed to be $2,400 \mathrm{~kg} / \mathrm{m}^{3}$ ) (Figure 1).

While it is more effective from energy efficiency point of view to adopt lightweight concrete for building envelope and floor slab, the structural engineers may concern the long term structural performance and durability. A compromise is to use lightweight concrete for prefabricated non-structural permanent formwork of the building envelope and shallow deck of floor slab while the structural wall or floor slab can be cast-in-situ with normal reinforced concrete (Figure 2). The lightweight permanent formwork can reduce the thermal conductivity of the external wall or slab significantly. Suppose the thickness and thermal conductivity of the lightweight permanent formwork $\left(1,500 \mathrm{~kg} / \mathrm{m}^{3}\right)$ and the reinforced concrete wall is $60 \mathrm{~mm}, 0.5 \mathrm{~W} / \mathrm{m} \cdot \mathrm{K}$, $180 \mathrm{~mm}$ and $1.3 \mathrm{~W} / \mathrm{m} \cdot \mathrm{K}$, respectively. The U-value of a normal reinforced concrete/lightweight permanent formwork composite is about $46 \%$ and $28 \%$ lower than normal concrete wall of thickness of $180 \mathrm{~mm}$ and $240 \mathrm{~mm}$, respectively.

When the moisture gradient in concrete is positive towards the environ- 
ment, the evaporable (non-chemically bonded) pore water in the specimen will diffuse to the surfaces and evaporate. This drying process results in moisture loss and shrinkage. Depending on the level of pore relative humidity $(h)$, one or a combination of the following drying-shrinkage mechanisms: capillary pressure, disjoining pressure, surface tension, pore blocking, and movement of interlayer water, can be activated. In the medium to high range of $h(50 \%$ $85 \%$ ), the shrinkage is attributed to the coaction of the changes in capillary and disjoining pressures during the drying process $[22,26,5]$. A concavecurved meniscus is formed in the pores due to moisture loss. The resulted change in the capillary pressure will compress the solid skeleton and lead to volumetric contraction. The moisture loss can also reduce the disjoining pressure in the areas of hindered water adsorption, which in turn decreases the separation between the solid surfaces. When $h$ is above $85 \%$, the movement of the evaporable water in the gel pores can be effectively blocked or slowed down by the link-bottle effect [26] and that is the major cause of the hysteresis of sorption isotherms [46]. In the low range of $h(<50 \%)$, the meniscus formation in the pores is unstable and the associated capillary pressure effect would become inactive. When drying occurs in this low range, the decrease of the disjoining pressure and increase of the surface tension between the cement gel particles $[22,56]$ are the major mechanisms for the shrinkage. When drying occurs below 25\%, the interlayer water adsorbed between CSH sheets can be removed and a more compact (i.e. reduction in volume) pore structure is formed $[25,26]$.

There are extensive review on the mechanical properties and thermal conductivity of lightweight aggregates and foamed concrete, which is referred to 
cementitious mortar without coarse aggregates and it is the adopted terminology in this study, however, little investigation on the drying shrinkage based on different formulation of the mix is available in literature [43]. The reported drying shrinkage of lightweight aggregates concrete ranges between 600 and 1,200 $\mu \varepsilon$ that depends on the aggregate type, aggregate content and initial saturation of the aggregates $[1,29,20]$. The drying shrinkage of foamed concrete ranges from $600 \mu \varepsilon$ to $3,000 \mu \varepsilon$ [43].

In this paper, different approaches of reducing the drying shrinkage of foamed concrete was investigated. The same approach is applicable for lightweight aggregates concrete. The formulation of foamed concrete was scaled up with the partnership of a concrete producer in a prefabricated yard and the drying shrinkage was compared with the existing strategies of the concrete producer. In addition, a new multi-physical hygro-mechanical model that couples the moisture transport in concrete, drying shrinkage and plastic strain evolution will be introduced. Based on the hygro-mechanical model, an incremental form of the stress-strain constitutive relationship will be derived so that it can be implemented in general finite element (FE) routine. The FE model can estimate the cracking potential under the action of diffusion and shrinkage of concrete skeleton and it can be extended to incorporate other mechanical and time-dependent (e.g. creep) action in the FE model. The model parameters were calibrated by the drying shrinkage data in this study and the crack pattern of typical configurations of building fasçade will be discussed. 


\section{Experimental details}

\subsection{Materials and chemicals}

In this study, the cementitious material consisted of ordinary Portland cement (OPC, CEM I 52.5), calcium sulfoaluminate (CSA) cement clinker (Grade 72.5, Score Tech Mortars Co. Ltd), ground granulated blast-furnace slag (GGBS, K.Wah Construction materials Limited), magnesium expansive agent (MEA, Score Tech Mortars Co. Ltd), limestone fine (LF, Score Tech Mortars Co. Ltd) and undensified condensed silica fume (SF, Elkem Microsilica Grade 920U). The particle size of OPC, GGBS, MEA, CSA and LF was in similar range (in 10-100 $\mu \mathrm{m}$ ). According to the datasheet of Elkem, the minimum specific surface area and maximum retention in 45 microns sieve of SF was $15 \mathrm{~m}^{2} / \mathrm{kg}$ and $10 \%$, respectively. The results of elemental analysis from X-ray fluorescence (XRF) spectroscopy of the as-received raw materials are shown in Table 1.

The roles of limestone fine are inert filler and the nucleation site for the hydration of OPC [34] and CSA cement [27]. The water demand for complete hydration of CSA cement depends on the dosage of gypsum and it is maximum at about $30 \% \mathrm{wt}$ while it is typical to add $15-25 \%$ wt of gypsum to CSA cement clinker [21]. The as-received CSA cement clinker was ground to particle size similar to OPC by the supplier and it was blended with $15 \%$ mass of industrial grade gypsum dihydrate $\left(C \bar{S} H_{2}\right.$, Score Tech Mortars Co. Ltd) in powder form with similar particle size with OPC in a pan mixer of the laboratory before mixing with other powder. It is referred as CSA-blend in the later part of the study.

MEA is a common admixture for expansive cement [42]. The MEA used 
in this study was lightly calcined industrial grade magnesium oxide. The as-received MEA was further calcined in an in-house furnace for 1 hour at $800^{\circ} \mathrm{C}, 900^{\circ} \mathrm{C}$ and $1000^{\circ} \mathrm{C}$, respectively. The purpose of further calcination was to increase the crystallinity and hence reduced the reactivity so that it could compensate the drying shrinkage in longer period.

To improve the workability of the mix in fresh state, high performance polycarboxylate based superplasticiser (BASF Glenium ACE 80) was used. Industrial grade boric acid (Score Tech Mortars Co. Ltd) in powder form was used to control the setting time of the mix with CSA-blend [10]. Since the mix contained all fine powder, industrial grade hydroxypropyl methylcellulose (HPMC, Score Tech Mortars Co. Ltd) and SF was added as viscosity modifying agent to improve the cohesiveness of the mix. The foaming agent used for the foamed concrete was fatty alcohol based liquid (BASF Rheocell 30), the main chemical compositions of which are 2-(2-butoxyethoxy) ethanol, dodecyl alcohol and tetradecanol mixed isomers according to the material safety data sheet from the supplier.

\subsection{Verification test}

Shrinkage is a characteristic material property. Any decrease of relative humidity impacts the capillary pressure, disjoining pressure and surface tension in the connected porosity [40]. In nanoscopic scale $(2-50 \mathrm{~nm})$ of mature cementitious materials, the effect on drying shrinkage by disjoining pressure is shown to be dominant over the change in capillary pressure and surface tension [9]. The driving force of drying shrinkage $\left(q_{h}\right)$ can be estimated by considering the thermodynamical equilibrium between water vapour and liquid water given by Kelvin's law in Eq. (1) [26, 58, 9]. 


$$
q_{h}=P_{g a s}-P_{l i q}=\frac{2 \delta w}{r_{h}}=-\frac{R T}{M V_{f}} \ln h
$$

where $P_{\text {gas }}$ is the water vapour pressure, $P_{l i q}$ is liquid water pressure, $\delta_{w}$ is water surface tension, $r_{h}$ is Kelvin's radius, $R$ is gas constant, $T$ is the absolute temperature, $M$ is molecular weight of water, $V_{f}$ is water volume that is equal to the volume of fully saturated pore and $h$ is the pore relative humidity. The capillary pressure is inversely proportional to the Kelvin's radius of pore. According to Ziembicka [60], the drying shrinkage of cellular lightweight concrete is mainly correlated to capillary pore with pore size ranged between 75 and $625 \AA$. In contrast, the bubble size distribution of entrained bubble in foamed concrete is mainly in the range of $10-150 \mu \mathrm{m}$ [15], which has much less effect on drying shrinkage compared to the existing capillary pore in the matrix. Based on the above argument, a hypothesis is made that the drying shrinkage of non-foamed concrete is similar to foamed concrete under the same mix formulation. This hypothesis is verified by comparing the drying shrinkage of 3 different mix formulations of both foamed and non-foamed concrete. After the hypothesis is verified, only the drying shrinkage of non-foamed concrete in normal density (about 2,000 kg/ $\mathrm{m}^{3}$ ) is investigated with different combinations of binder and filler without incorporating preformed foam or foaming agent.

\subsection{Mix design of the verification test between foamed and non-foamed con-} crete

To compare the drying shrinkage between non-foamed concrete (normal mortar) and foamed concrete, three sets of mix were selected as shown in Ta- 
ble 2. The target compressive strength of foamed concrete was about $40 \mathrm{MPa}$ and the wet density of foamed concrete was set at around $1,600 \mathrm{~kg} / \mathrm{m}^{3}$ [30]. The first set was the blend of OPC and GGBS with mass ratio of OPC:GGBS $=2: 1$. The second set was the blend of OPC, GGBS and SF with mass ratio of OPC:GGBS = 1:3.2 plus 3\% SF of the total mass of all powder (including itself). The third set was the blend of OPC, GGBS, SF and LF with mass ratio of OPC:GGBS = 1:3.2 plus $3 \% \mathrm{SF}$ and $20 \% \mathrm{LF}$ of the total mass of all powder. The water to powder ratio was fixed at 0.285 . The foamed concrete samples were made by adding foaming agent of $0.15 \%$ mass of the all powder in the wet mix [17] instead of using preformed foam. The water to powder ratio, the amount of foaming agent, SP, SF and HPMC was determined by trial-and-error to achieve the rheological properties and target wet density of both non-foamed and foamed sample without segregation and excessive bleeding in the Hobart Mixer HSM 20 used in the laboratory. When foaming agent was added, the viscosity of the wet mix increased significantly. If the workability of the mix was too low, entrained bubbles by foaming were coalesced by excessive shear stress during mixing that reduced the compressive strength of foamed concrete significantly. It was the major reason to keep the water content of the mix similar even through it increased the water-tobinder ratio when binder was replaced by LF (N3 and F3). For each mix formulation, there were three $100 \mathrm{~mm}$ cubic samples for compression test and three $40 \mathrm{~mm} \times 40 \mathrm{~mm} \times 300 \mathrm{~mm}$ prismatic samples for drying shrinkage measurement. 


\subsection{Mix design of non-foamed concrete}

After the hypothesis of using the drying shrinkage of non-foamed concrete to approximate the foamed concrete counterpart was verified in 2.3, the compressive strength and drying shrinkage of three different strategies of mix design of non-foamed concrete was investigated. The three groups of mix design were (i) OPC-GGBS-LF blend (GI), (ii) OPC-GGBS-MEA-LF blend (GII) and (iii) OPC-GGBS-CSA-LF blend (GIII). There were 15 mixes in total and the detail mix formulations are shown in Table 3. The rationale behind each group is explained in the following.

\subsubsection{Group I (GI), OPC-GGBS-LF blend}

The first group was the blend of OPC, GGBS and LF. The purpose of the first group was to reconstruct the reference of conventional composition of foamed concrete. Supplementary cementitious material GGBS was used to substitute OPC in order to reduce carbon footprint. In this study, GGBS was considered but not fly ash because the foaming agent was sensitive to unburned carbon of fly ash that might affect the foam stability from past experience of the authors. There were 5 mix formulations in GI. The effect of drying shrinkage of different mass ratios between OPC and GGBS was investigated from the first 4 mixes in group I (GI-1 to GI-4). In GI-5, part of OPC was replaced by LF to investigate the effect on drying shrinkage by reducing the binder content. In all mix in GI, $3 \% \mathrm{SF}, 0.125 \% \mathrm{SP}$ and $0.005 \%$ HPMC to the total mass of all powder was added. The water to powder ratio was fixed at 0.285 as determined by the trial-and-error in the verification test. 


\subsubsection{Group II (GII), OPC-GGBS-MEA-LF blend}

The second group was the blend of OPC, GGBS, MEA and LF. In the previous study, the long-term (over 20 years) drying shrinkage of concrete with 3.5-6\% mass dosage of MEA and 20-30\% mass of fly ash was measured $[38,42]$. All concrete with MEA in [38] showed volumetric expansion and most expansion happened in the first year of the testing. The formulation of GII was based on GI-4 and 4\% MEA with four different degrees of calcination to the total mass of all powder was added.

MEA is conventionally used as expansive agent to compensate autogenous and drying shrinkage of OPC. The hydration reaction between MEA and water to form magnesium hydroxide in Eq. (2) is expansive.

$$
\mathrm{MgO}+\mathrm{H}_{2} \mathrm{O} \rightarrow \mathrm{Mg}(\mathrm{OH})_{2}
$$

The reactivity of hydration of MEA depends on the concentration of surface defects of the $\mathrm{MgO}$ crystals. The less defects of $\mathrm{MgO}$ crystals, the slower the hydration rate but higher ultimate expansion [41, 42]. When magnesite is calcined under high temperature, it is firstly decomposed into $\mathrm{MgO}$ nanoparticles and they are sintered and coarsen to form $\mathrm{MgO}$ grain and the crystal defects are reduced [32]. The higher calcination temperature and longer residence time, the larger the $\mathrm{MgO}$ crystal size and less defect of $\mathrm{MgO}$ crystal that leads to lower specific area for reaction. When the defect of $\mathrm{MgO}$ crystal is reduced, more hydration product of $\mathrm{MgO}$ is forced to form on the exterior surface of the crystal. The combined effect is slower hydration rate but higher ultimate expansion. 


\subsubsection{Group III (GIII), OPC-GGBS-CSA-LF blend}

The third group was the blend of OPC, GGBS, CSA-blend, and LF. All mixes consisted of $3 \% \mathrm{SF}, 0.125 \% \mathrm{SP}$ and $0.005 \% \mathrm{HPMC}$ of the total mass of all powder. The water to powder ratio varied and it will be explained later.

CSA is used for shrinkage compensation of OPC [12,2]. The major phases of CSA cement clinker were ye'elimite $\left(\mathrm{C}_{4} \mathrm{~A}_{3} \bar{S}\right)$ and belite $\left(\alpha-\mathrm{C}_{2} \mathrm{~S}\right)$ from the XRD pattern in Figure 3. The hydration of ye'elimite depends on the availability of $C \bar{S} H_{2}$ and calcium hydroxide $(C H)[36,21,45,55]$. The hydration products of pure ye'elimite are monosulfate and aluminium hydroxide $\left(\mathrm{AH}_{3}\right.$, Eq. (3)). The reaction rate is very slow and the setting time is usually more than 3 hours. When $C \bar{S} H_{2}$ is available, the hydration products of ye'elimite are ettringite and $A H_{3}$ (Eq. (4)). While $C H$ and $C \bar{S} H_{2}$ is available, the hydration product of ye'elimite is purely ettringite (Eq. (5)). The hydration reaction of CSA-blend in this study was dominated by Eq. (4) and Eq. (5). If the amount of $\mathrm{CH}$ is not enough to hydrate all ye'elimite, belite reacts with $A H_{3}$ from either Eq. (3) or Eq. (4) to form strätlingite $\left(C_{2} A S H_{8}\right)$ in Eq. (6).

$$
\begin{gathered}
C_{4} A_{3} \bar{S}+18 H \rightarrow C_{3} A \cdot C \bar{S} \cdot 12 H+2 A H_{3} \\
C_{4} A_{3} \bar{S}+2 C \bar{S} H_{2}+34 H \rightarrow C_{3} A \cdot 3 C \bar{S} \cdot 32 H+2 A H_{3} \\
C_{4} A_{3} \bar{S}+C \bar{S} H_{2}+74 H+6 C H \rightarrow 3 C_{3} A \cdot 3 C \bar{S} \cdot 32 H \\
C_{2} S+A H_{3}+5 H \rightarrow C_{2} A S H_{8}
\end{gathered}
$$

Since the setting time of CSA-blend was as short as 15 minutes, boric acid powder is added to retard the setting time to $60-75$ minutes [10]. The 
dosage of boric acid was determined from trial-and-error process [7] for each formulation. The dosage of boric acid in Table 3 is the ratio to the total weight of OPC and CSA-blend only. The total water content was adjusted empirically so that the mix in the fresh state maintained similar rheological properties because the effectiveness of SP to CSA-blend was different from OPC and GGBS.

There were six mixes in the GIII. GIII-1 and GIII-3 were the mix of CSAblend without and with $20 \%$ LF to the total mass of all powder, respectively. GIII-2 was the mix of GGBS and CSA-blend to investigate whether CSAblend can activate GGBS without OPC. GIII-4, GIII-5 and GIII-6 were the blend of OPC, GGBS, CSA-blend. The ratio between OPC and CSA-blend in GIII-4 was 1:1 while that of GIII-5 and GIII-6 was 1:2. $40 \%$ LF to the total mass of all powder was added in GIII-6.

\subsection{Specimens preparation and test}

\subsubsection{Sample preparation}

All dry powder including OPC, GGBS, CSA-blend, SF, LF, MEA, boric acid powder and HPMC were mixed at the lowest speed of Hobart Mixer HSM 20 for 5 minutes. Superplasticiser (SP) was mixed with water thoroughly before adding to the mixed dry powder.

To fabricate foamed concrete, SP was mixed with $80 \%$ of the total water content while liquid form foaming agent was mixed with the remaining $20 \%$ water separately. The $80 \%$ water $+100 \%$ SP was thoroughly mixed with the dry powder mix. After the SP was effective, $20 \%$ water $+100 \%$ foaming agent was added to the wet mix to produce lightweight foamed concrete. The wet density of the sample was measured in $100 \mathrm{~mm}$ cubes. 
For each mix, three cubic samples were prepared for wet density measurement and compressive strength test. In the same batch of wet mixture, three $40 \mathrm{~mm} \times 40 \mathrm{~mm} \times 300 \mathrm{~mm}$ prisms were prepared for drying shrinkage measurement. A bolt was embedded at each end of the prism.

All samples were covered by cling wrap and cured at room temperature in the laboratory for 24 hours then the samples were demoulded. The initial length of the prismatic samples was measured by a dial gauge manually [8]. Afterwards, the cubic and prismatic samples were further cured in water bath at $60^{\circ} \mathrm{C}$ for 7 days and at room temperature for 2 days, respectively.

\subsubsection{Drying shrinkage measurement}

After the prismatic samples were taken out from water bath at room temperature, they were wiped by a dry towel to remove the water on surface. Then, the initial length of prismatic sample was measured and it was corresponding to the day zero in the subsequent result reporting sections. The samples were put in a room regulated at $23 \pm 1^{\circ} \mathrm{C}$ and $55 \pm 5 \%$ relative humidity. The graphs of the reported drying shrinkage consisted of the average value of the three samples and the error bars. The error bars were corresponding to the $90 \%$ confidence interval obtained by $\mu \pm t_{0.05,2} \cdot \sigma / \sqrt{2}=\mu \pm 2.920 \sigma / \sqrt{2}$, where $t_{0.05,2}$ is the upper 5 percentage point of the t-distribution with 2 degrees of freedom, $\mu$ and $\sigma$ are the mean and standard deviation of the three samples, respectively.

\subsubsection{Compressive strength measurement}

Before the compression test, all $100 \mathrm{~mm}$ cubic samples were air dried for another 7 days after immersing in $60^{\circ} \mathrm{C}$ water bath for 7 days. The reported 
compressive strength was the average of three samples from the same batch of mix and identical curing condition. It was corresponding to the 15th day from sample casting. Although it was not a conventional testing condition for compressive strength of cementitious material, it provided comparative strength of different mixes while the compressive strength was not the main focus in this study.

\section{Hygro-mechanical model for simulation of shrinkage}

This section discusses a hygro-mechanical model to simulate the diffusion, shrinkage and plastic strain evolution of concrete. Then, the incremental stress-strain constitutive relationship will be derived so that it can be incorporated in general FE model. The model parameters will be calibrated by the drying shrinkage data in this study in section 5. Simulation examples will be demonstrated in section 7 .

\subsection{Drying shrinkage and transport of moisture}

The interested $h$ range in this study is above 50\%. The main driving force $\left(q_{h}\right)$ of drying shrinkage can be estimated by Kelvin's law in Eq. (1). The resulted shrinkage strain $\left(\varepsilon^{s h}\right)$ can be calculated by Eq. (7) [22].

$$
\varepsilon^{s h}=\frac{\alpha_{H} q_{h} \xi}{3}\left[\frac{1}{K}-\frac{1}{K_{s}}\right]
$$

where $\alpha_{H}$ is a constant parameter [37]; $K$ is the bulk modulus of the porous medium; $K_{s}$ is the bulk modulus of the solid skeleton; $\xi$ is the saturation factor, which can be approximated in relation to the pore relative humidity $h$ by Eq. (8) [37, 4],

$$
\xi=1-0.75\left[1-\left(\frac{h}{0.98}\right)^{3}\right]
$$


The bulk moduli $K$ and $K_{s}$ can be related by Biot's coefficient $b$ in Eq. (9).

$$
b=1-\frac{K}{K_{s}}
$$

The transport of water in porous media is a diffusion-controlled process and can be described by the classic Fick's second law of diffusion [18]. If one assumes that the pore gas pressure is equal to the atmospheric pressure and the moisture capacity of concrete remains constant within the $h$ range of $50 \%-100 \%$, the transport of pore moisture can be modelled in Eq. (10) [23].

$$
\frac{\partial h}{\partial t}=-\nabla \cdot\left(D_{e f f}(h) \nabla h\right)
$$

Note that if other types of shrinkage such as autogenous shrinkage are also considered, then the corresponding time-dependent terms shall be added to the right-hand side of Eq. (10) [23]. For uncracked concrete, the effective diffusion coefficient can be expressed in Eq. (11) [23].

$$
D_{e f f}(h)=D_{0}\left[1+f(h)\left(\alpha_{D}-1\right)\right]
$$

where $\alpha_{D}=\frac{D_{1}}{D_{0}}$, in which $D_{0}$ is the minimum of $D_{\text {eff }}(h)$ for $h=0 ; D_{1}$ is the maximum of $D_{\text {eff }}(h)$ for $h=1 ; f(h)$ is a hyperbolic function given by Eq. 12.

$$
f(h)=\frac{h \cdot e^{-\beta}}{1+h\left(e^{-\beta}-1\right)}
$$

where $\beta$ is a shape factor. The moisture flux $\nabla h_{b}$, expressed in term of the relative humidity, through the boundaries of the medium can be modelled by a convective boundary condition [23].

$$
\nabla h_{b}=k_{h}\left(h_{b}-h_{e n v}\right)
$$


where $h_{b}$ and $h_{e n v}$ are the relative humidities of the boundary and environment, respectively. Eq. (13) describes an imperfect moisture transfer on the exposed surface. For perfect moisture transfer, $h_{b}=h_{e n v}$, as the surface emissivity $k_{h} \rightarrow \infty$.

\subsection{Mechanical responses}

If the drying shrinkage is restrained, tensile stress is induced in concrete and micro-cracks can develop mainly perpendicular to the gradient of the pore humidity when the tensile strength is exceeded. The strength of concrete under multiaxial states of stress can be evaluated by Ottosen's fourparameter yield criterion $[44,13]$.

$$
F=\alpha_{p} J_{2}+\sigma_{c}\left(\xi_{p}\right)\left[\lambda(\theta) \sqrt{J_{2}}+\beta_{p} I_{1}\right]-\sigma_{c}^{2}\left(\xi_{p}\right)=0
$$

in which the hardening parameter $\sigma\left(\xi_{p}\right)=\sqrt{\varepsilon_{\mathbf{p}} \cdot \varepsilon_{\mathbf{p}}}$ is assumed to be a function of the equivalent inelastic strain $\varepsilon_{p}$. In Eq. (14), $\lambda(\theta)$ defines the cross section of the yield function on the deviatoric plane and it is a function of Lode angle $\theta$ which can be estimated by Eq. (15).

$$
\lambda(\theta)= \begin{cases}c_{p} \cos \left(\frac{1}{3} \cos ^{-1}\left(d_{p} \cos 3 \theta\right)\right), & \cos 3 \theta \geq 0 \\ c_{p} \cos \left[\frac{\pi}{3}-\frac{1}{3} \cos ^{-1}\left(-d_{p} \cos 3 \theta\right)\right], & \cos 3 \theta<0\end{cases}
$$

The parameters $c_{p}$ and $d_{p}$ control the size and the shape of the cross section, respectively. The four material parameters $\alpha_{p}, \beta_{p}, c_{p}$ and $d_{p}$ can be calibrated from uniaxial and multiaxial strength tests. The direction of the inelastic strain increment is described by the flow potential function, for which the classic Drucker-Prager hyperbolic function is given by Eq. (16).

$$
G=\sqrt{J_{2}+\left(e \cdot f_{c t} \tan \Psi\right)^{2}+I_{1} \tan \Psi}
$$


where $\Psi$ is the dilation angle measured in space at high confining pressure, $e$ is eccentricity of the flow potential, and $f_{c t}$ is the uniaxial tensile strength. In Eqs. (14) and (16), the invariants of the stress tensor $\sigma=\sigma_{i j}$ are calculated in Eq. (17)

$$
\begin{aligned}
I_{1} & =\sigma_{i i} \\
J_{2} & =\frac{1}{2} s_{i j} s_{i j} \\
J_{3} & =\frac{1}{3} s_{i j} s_{j k} s_{k i} \\
\cos 3 \theta & =\frac{3 \sqrt{3}}{2} \frac{J_{3}}{J_{2}^{3 / 2}}
\end{aligned}
$$

$\sigma_{i j}-\sigma_{k k} \cdot \delta_{i j} / 3$ is the deviatoric stress tensor. Since the flow potential function in Eq. (16) is different from the yield function in Eq. (14), the inelastic strain rate $\dot{\varepsilon_{\mathbf{p}}}$ follows the non-associate flow rule in Eq. (18).

$$
\dot{\varepsilon_{\mathbf{p}}}=\dot{\lambda} \frac{\partial G}{\partial \sigma}
$$

The rate of the plastic multiplier $\dot{\lambda}$ is determined from the Kuhn-Tucker loading condition in Eq. (19).

$$
\begin{cases}\dot{\lambda} & \geq 0 \\ F & \leq 0 \\ \dot{F} & =0 \\ \dot{\lambda} \cdot F & =0\end{cases}
$$


403

404

409

exponentially after the peak stress $f_{t}=k_{t} f_{c}$ in Eq. (20) [33].

$$
k_{t} \cdot \sigma_{c}\left(\xi_{p}\right)= \begin{cases}E_{c} \cdot \varepsilon_{t}, & \sigma_{t} \leq f_{t} \\ f_{t} \cdot e^{-\xi_{p} / \gamma_{p t}}, & \sigma_{t}>f_{t}\end{cases}
$$

where $k_{t}$ is the ratio of the uniaxial tensile strength to the uniaxial compressive strength; $\xi_{p}=\varepsilon_{t}-\varepsilon_{0}$ is the cracking strain in which $\varepsilon_{t}$ is the tensile strain at the peak stress $f_{t}$. The effects of ageing $t_{a}$ (in days) on the compressive strength $f_{c}$ and elastic modulus $E_{c}$ of concrete are modelled by Eq. (21) [11].

$$
\left\{\begin{array}{l}
f_{c}\left(t_{a}\right)=f_{c, 28} e^{s\left(1-\sqrt{\frac{28}{t_{a}}}\right)} \\
E_{c}\left(t_{a}\right)=E_{c, 28} e^{0.5 s\left(1-\sqrt{\frac{28}{t_{a}}}\right)}
\end{array}\right.
$$

in which $f_{c, 28}$ and $E_{c, 28}$ are the strength and elastic modulus at an age $t_{a}$ of 28 days; $s$ is a coefficient which depends on the aggregate type and strength class of cement. The area under the stress-strain curve, which depends on the characteristic length $\ell_{e q}$ of the element, is controlled by $\gamma_{p t}$ defined in Eq. (22) [33].

$$
\gamma_{p t}=\frac{G_{f}}{\ell_{e q} f_{c t}}-\frac{1}{2} \frac{f_{c t}}{E_{c}}
$$

The use of the parameter $\gamma_{p t}$ can mitigate the spurious mesh sensitivity and ensure the energy dissipation in an element, where the crack opening is smeared and represented by the equivalent cracking strain $\xi_{p}$, to be consistent with the fracture energy $G_{f}$.

\subsection{Incremental stress-strain relationship}

The effects of shrinkage on the cracking potential of concrete structures are the major interests of engineers. The behaviour of concrete structures 
433

under drying can be studied by FE methods. To implement the above hygromechanical model in general FE routine, an incremental form of the constitutive relationship shall be established. Based on the series model, the total strain increment $\Delta \varepsilon_{i}$ at time step $i$ is the linear combination of the elastic strain increment $\Delta \varepsilon_{i}^{e}$, shrinkage increment $\Delta \varepsilon_{i}^{s h}$, and instantaneous inelastic increment $\Delta \varepsilon_{\boldsymbol{i}}^{\boldsymbol{p}}$ as in Eq. (23).

$$
\Delta \varepsilon_{\mathbf{i}}=\Delta \varepsilon_{i}^{e}+\Delta \varepsilon_{i}^{s h} \mathbf{I}+\Delta \varepsilon_{\mathbf{i}}^{\mathbf{p}}
$$

where $\mathbf{I}=\left[\delta_{i j}\right]$ is the $3 \times 3$ identity matrix. The stress increment $\Delta \boldsymbol{\sigma}_{\boldsymbol{i}}$ is always related to the elastic strain increment $\Delta \varepsilon_{\mathbf{i}}^{\mathbf{e}}=\mathbf{D}_{\mathbf{e}}^{-1} \cdot \Delta \sigma_{\mathbf{i}}$ in which $\mathbf{D}_{\mathbf{e}}$ is the age-dependent elastic stiffness matrix in Eq. (24).

$$
\mathbf{D}_{\mathbf{e}}=E_{c}\left(t_{a}\right)\left[\begin{array}{cccccc}
1 & -\nu & -\nu & 0 & 0 & 0 \\
-\nu & 1 & -\nu & 0 & 0 & 0 \\
-\nu & -\nu & 1 & 0 & 0 & 0 \\
0 & 0 & 0 & 2(1+\nu) & 0 & 0 \\
0 & 0 & 0 & 0 & 2(1+\nu) & 0 \\
0 & 0 & 0 & 0 & 0 & 2(1+\nu)
\end{array}\right]
$$

Eqs. 14-19 into Eq. 23, then an incremental stress-strain relation is obtained in Eq. (25).

$$
\Delta \boldsymbol{\sigma}_{\boldsymbol{i}}=\mathrm{D}_{\mathrm{ep}} \cdot\left(\Delta \varepsilon_{\mathbf{i}}-\Delta \varepsilon_{i}^{s h} \mathbf{I}\right)
$$

where $\mathbf{D}_{\mathbf{e p}}=\mathbf{D}_{\mathbf{e}}+\mathbf{D}_{\mathbf{p}}$ is the incremental stiffness (Jacobian) matrix at time step $i$. The degradation of the material stiffness due to cracking is represented by the plastic stiffness tensor $\mathbf{D}_{\mathbf{p}}$ in Eq. (26).

$$
\mathbf{D}_{\mathbf{p}}=-\frac{\left(\mathbf{D}_{\mathbf{e}} \cdot \frac{\partial G}{\partial \boldsymbol{\sigma}}\right) \otimes\left(\frac{\partial F}{\partial \boldsymbol{\sigma}} \cdot \mathbf{D}_{\mathbf{e}}\right)}{H+\left(\frac{\partial F}{\partial \boldsymbol{\sigma}} \cdot \mathbf{D}_{\mathbf{e}} \cdot \frac{\partial G}{\partial \boldsymbol{\sigma}}\right)}
$$


where $H$ is the softening parameter calculated by Eq. (27).

$$
H=-\frac{\partial F}{\partial \xi_{p}}\left(\frac{\partial \xi_{p}}{\partial \boldsymbol{\varepsilon}^{p}} \cdot \frac{\partial G}{\partial \boldsymbol{\sigma}}\right)
$$

The coupled hygro-mechanical problem is a 2-field problem, which is described by the vector field of displacement $\mathbf{u}$ and the scalar field of pore relative humidity $h$. During time step $i$, each Gauss point or integration point of an element is provided with the increments of strain and relative humidity, which are interpolated from the nodal values using the prescribed shape function. In each Gauss point, the incremental constitutive equations are numerically integrated using the modified explicit Euler scheme with substepping [49]. The coupled hygro-mechanical constitutive model described above was implemented in ABAQUS using user-subroutine UMAT [24].

\section{Results and discussions of laboratory experiment}

\subsection{Verification test}

\subsubsection{Compressive strength}

The compressive strength of the three selected mix formulations of verification test is shown in Table 2. The compressive strength of the three foamed and non-foamed concrete specimens was about $40 \mathrm{MPa}$ and $90 \mathrm{MPa}$, respectively.

\subsubsection{Drying shrinkage}

Figure 4 shows the micrographs of foamed concrete in the verification test. The density was about $1,500 \mathrm{~kg} / \mathrm{m}^{3}$. The diameter of the entrained bubble was mainly between 10 and 150 micron. Figure 5a shows the drying 
shrinkage of the non-foamed and foamed concrete. Although the compressive strength of the three selected non-foamed concrete formulations was similar, the magnitude of drying shrinkage was significantly different (varied from $2,000 \mu \varepsilon$ to more than 3,000 $\mu \varepsilon)$. In Figure $5 \mathrm{a}$, the trend and magnitude of drying shrinkage of foamed concrete is very close to the non-foamed counterparts. It is consistent to the finding in [60] that the drying shrinkage was essentially contributed by the capillary pores between 75 and $625 \AA$ and there was little effect of the entrained bubble by foaming on drying shrinkage in all age in the test. Hence, it is justifiable to investigate the drying shrinkage of foamed concrete by measuring the drying shrinkage of non-foamed concrete counterpart.

\subsection{Non-foamed concrete - GI}

\subsubsection{Compressive strength}

For GI, the compressive strength of those mixes of the blend of OPCGGBS was similar (between 90 and $106 \mathrm{MPa}$ in Table 3) except GI-2 (about $41 \mathrm{MPa})$, which did not contain any OPC.

\subsubsection{Drying shrinkage}

The expansive strain of GI during water curing is shown in Table 3. The reference length of the expansive strain was taken from the length of the sample after demoulding before putting into water bath. The expansion of OPC-GGBS blends (GI-2, GI-3 and GI-4) was significantly higher (157\% in average) compared with OPC mixes (GI-1 and GI-5). The results of drying shrinkage test of GI are shown in Figure 5b. The reference length of the drying shrinkage shown was corresponding to the length after water 
curing. All drying shrinkage on the 28th day (the 31st day after casting) was generally beyond $2,000 \mu \varepsilon$ which was several times higher than normal concrete. There was little impact on drying shrinkage from replacing binder by LF (GI-1 and GI-5). The drying shrinkage of those mixes with GGBS was generally higher (GI-2, GI-3 and GI-4). When $75 \%$ mass of OPC was replaced by GGBS (GI-4), the drying shrinkage on the 28th day was increased by $50 \%$ compared with the pure OPC mix (GI-1), which was consistent to the finding in [48]. The drying shrinkage of the pure GGBS (GI-2) was lower compared to OPC-GGBS blends (GI-3 and GI-4). However, the rate of increase of drying shrinkage was higher than other mixes because the reactivity of pure GGBS in GI-2 was much slower.

\subsection{Non-foamed concrete - GII}

\subsubsection{Compressive strength}

The compressive strength of GII is higher for higher calcination temperature of MEA and it was all higher than the compressive strength of the reference OPC-GGBS blend in GI-4 (Table 3).

\subsubsection{Drying shrinkage}

The expansive strain of GII during water curing is shown in Table 3. The expansion of the as-received MEA (GII-1) was significantly lower than (40\% in average) compared with other mixes in GII. The reason may be because of the incomplete calcination of the as-received MEA. In this study, the use of MEA did not reduce drying shrinkage of the reference mix GI-4 significantly (Figure 5c). Unlike the reports from literature that with significant expansion with as low as $4 \%$ wt of MEA, the curing conditions of those reports 
were completely different from this study. For example, the curing conditions were room temperature in water [38] and $20^{\circ} \mathrm{C}$ at $90 \%$ R.H. [19]. For GII-1, which contained $4 \%$ as-received MEA, showed the least drying shrinkage in GII. One possible explanation was that the hydration reaction of $\mathrm{MgO}$ in Eq. (2) was halted by the depletion of water shortly after the drying shrinkage test started. The reactivity of the as-received MEA was the fastest and the crystallinity was the lowest so that it was fast enough to compensate the drying shrinkage at early age. It can be verified from Figure 5c that the drying shrinkage on the 7th day of the shrinkage test (the 10th day after casting) of GII-1 was significantly lower than the other three sets. Another possible reason of less MEA expansion observed in this study (with GGBS) compared to other studies with fly ash $[38,42]$ was that the $\mathrm{pH}$ value of the pore solution with GGBS was lower than fly ash because the pozzolanic reactivity of GGBS is higher. Then, the supersaturated degree of $\mathrm{Mg}^{2+}$ was lower in lower $\mathrm{pH}$ environment and it reduced the expansion near $\mathrm{MgO}$ particle [42].

\subsection{Non-foamed concrete-GIII}

\subsubsection{Compressive strength}

The compressive strength of GIII was significantly reduced when the mass ratio of CSA-blend to OPC was less than 2:1 (Table 3). One of the possible reasons was that part of $C \bar{S} H_{2}$ reacted with tricalcium aluminate $\left(C_{3} A\right)$ in OPC so that there was not enough $C \bar{S} H_{2}$ to react with ye'elimite in CSA-blend and the hydration product of CSA-blend became monosulfate (Eq. (3)). When CSA-blend was blended with GGBS without OPC (GIII-5), the compressive strength was about one-third of pure CSA-blend (GIII-1). It was because the alkalinity and reactivity of GGBS was lower than OPC. 


\subsubsection{Drying shrinkage}

The expansive strain of GIII during water curing is shown in Table 3. The expansion of GIII-4 was significantly lower than other mixes in GIII. It was because there was not enough gypsum for CSA hydration when OPC:CSA was 1:1. The expansion of GIII-3 was significantly higher than GIII-1. It was because of the nucleation effect of LF to accelerate the hydration of CSA [27]. The drying shrinkage of GIII was significantly lower than GI and GII (Figure 5d). GIII-1 with pure CSA-blend was the reference in GIII. The drying shrinkage on the 28th day (the 31st day after casting) of GIII-1 was about $40 \%$ of the pure OPC case (GI-1). When about $75 \%$ of CSAblend was replaced by GGBS (GIII-2), the drying shrinkage on the 28th day was about $68 \%$ of GIII-1. It was because when GGBS contacts with water, calcium hydroxide $(\mathrm{CH})$ was released and the hydration reaction of CSA-blend was changed from Eq. (4) to Eq. (5), which consumed much more water for hydration and hence less free water was left for drying shrinkage. Although GGBS consumed CH through pozzolanic reaction, it happened only after 2 to 3 days [6] while all $C \bar{S} H_{2}$ was consumed in 48 hours according to the XRD result in [21]. So, pozzolanic reaction of GGBS followed the complete hydration reaction of CSA-blend in Eq. (5). When about 20\% of CSA-blend was replaced by LF (GIII-3), the drying shrinkage increased dramatically. When CSA-blend was replaced by LF and there was no $\mathrm{CH}$ provided, the water consumption during hydration of CSA-blend was less (Eq. (4)) and there was more free water left in the mix and contributed higher drying shrinkage.

From the previous argument, $\mathrm{CH}$ was beneficial to reduce the drying 
shrinkage of the blend of CSA-blend that the drying shrinkage should be lower by using OPC. However, when OPC-CSA-blend ratio was kept at 1:1 (GIII-4) and 20\% LF of the total mass of all powder, the drying shrinkage was about 11\% higher than GIII-1. Although OPC provided CH for CSAblend to form denser matrix, the additional $C \bar{S} H_{2}$ was consumed by OPC to react with $C_{3} A$ and monosulfate to form ettringite. Hence, there was not enough $C \bar{S} H_{2}$ for CSA-blend and the hydration of CSA-blend became Eq. (3) and it could be verified by observing the compressive strength of GIII-4 is lower than GIII-1 and the micrographs in Figure 6 of foamed sample. There were needle-like crystals formed in GIII-5 (Figure 6b) compared with GIII-4 (Figure 6a). Although there is no further characterisation of the crystals, it may be ettringite by comparing them with the micrographs in [50]. In addition, it resulted higher amount of free water remained in GIII-4 than GIII-1 because the water demand of Eq. 3 of GIII- 4 was less than GIII-1 from Eq. 4 with the same given water content. However, LF acted as nucleation site to accelerate the hydration of CSA-blend that explained the observation of the trends of drying shrinkage of GIII-1 and GIII-4 are similar. When the OPC to CSA-blend ratio was increased to 1:2 (GIII-5), the drying shrinkage was significantly reduced compared to all other mix in GIII. The reason was that the amount of $C \bar{S} H_{2}$ from CSA-blend was enough for both hydration of ye'elimite in CSA clinker and $C_{3} A$ of OPC. Hence, the free water remained in the matrix was the least in all GIII mixes.

There was $40 \%$ LF to the total mass of all powder in GIII-6. However, the drying shrinkage of GIII-6 was much higher than GIII-5. The addition of LF does not change the water demand of the reaction significantly so the 
free water remained in the mix was higher and hence it resulted of higher drying shrinkage.

In summary, the key factors to determine the magnitude of drying shrinkage in GIII are (i) the free water content and (ii) the hydration reaction (Eq. (4), Eq. (5) or Eq. (3)), which determines the total water consumed in hydration.

\subsection{Summary of the drying shrinkage test of GI, GII and GIII}

Although the drying shrinkage approaches asymptotic value in long term, to compare the relationship of expansion during the curing stage, rate of drying shrinkage and the drying shrinkage at the 28th day after the test, the dry shrinkage versus time graph are plotted in semi-log scale of time, the relationship can be approximated by a linear line (Figure 7). Table 4 shows the best-fitted coefficients and the $\mathrm{R}^{2}$ by using the least square method of the experimental drying shrinkage data in Eq. (28).

$$
\varepsilon^{s h}(t)=a \ln \left(\frac{t}{28}\right)+c
$$

where $a$ and $c$ are constants, $t$ is time in days and $\varepsilon^{s h}$ is the shrinkage strain. $c$ is the drying shrinkage on the 28th day (the 31st day from casting) and $a$ is the exponent that indicates the rate of increase of drying shrinkage. All data shows $R^{2}>0.9$ except GIII-5 $\left(R^{2}=0.898\right)$. In general, the drying shrinkage on the 28th day of GIII is about half of GI and GII. Also, the rate of increase of drying shrinkage of GIII, in general, was about half of GI and GII. Hence, the use of CSA-blend to control drying shrinkage is an effective approach and it is consistent to the finding in [2]. 
To compare the expansive strain during curing, the rate of drying shrinkage $(a)$ and the 28th day drying shrinkage $(c)$ in Table 4, There is no strong relationship observed between the initial expansion during the curing stage and drying shrinkage in testing stage.

\section{Calibration of the model parameters}

The materials with the lowest drying shrinkage in each group: GI-5, GII-1 and GIII-5 are further investigated for their feasibility in developing full-scale foamed concrete member, on which the time variation of drying shrinkage is simulated using the coupled hygro-mechanical FE models and compared with the experimental results in section 4 . The four parameters of the Ottosen yield criterion can be calibrated by the following strength data at an age $t_{a}$ of 28 days: uniaxial compressive strength $f_{c, 28}$, uniaxial tensile strength $f_{t, 28}=k_{t} f_{c, 28}$, equal biaxial compressive strength $f_{b c, 28}=1.16 f_{c, 28}$, and the triaxial stress states on the compressive and tensile meridians. Following the approach of Ottosen [44], the parameters for each material are adjusted using the least square method to give the best fits of both compressive and tensile meridians. Figure 8a shows the comparison of the triaxial test data (after Ottosen [44]) with the fitted Ottosen yield criterion in the meridian planes for foamed GI-5. The effects of aging on the strength and stiffness are modelled by Eq. (21), where the coefficient $s$ is taken as 0.2. The yield surface evolves with the equivalent plastic strain $\xi_{p}$, which the rate of strength degradation as described by Eq. (20) is governed by the fracture energy $G_{f}$. The simulated uniaxial tensile stress-displacement curves are plotted in Figure 8b. The calibrated material elastoplastic parameters for GI-5, GII-1 and GIII-5 are 
provided in Table 5 .

The material parameters for the drying shrinkage model, as shown in Table 6, are calibrated using the data from the drying shrinkage test results in section 4 . The values of the gas constant and molar volume of water at the room temperature are given as $8.31 \mathrm{~J} \cdot \mathrm{mol}^{-1} \cdot \mathrm{K}^{-1}$ and $18 \mathrm{~cm}^{3} \cdot \mathrm{mol}^{-1}$, respectively. The models are meshed using 8-node linear solid elements as shown in Figure 9a. The boundary conditions of ambient temperature and relative humidity are defined in Figure $9 \mathrm{~b}$ to reflect the actual test conditions. Good agreements between the simulated drying shrinkage curves and the test results can be seen in Figure 10a.

The cross-sectional shrinkage distributions due to drying are also captured by the models. Figures 10b-d show the simulated evolutions of shrinkage distributions across the mid-section C-C as marked in Figure 9. The dryingshrinkage always has the maximum values on the surfaces and its values gradually decrease with the depth from the surface until reaching its minimum values on the mid-planes. When the internal moisture gradually diffuses to the surfaces and evaporates to the environment, equilibrium of the internal relative humidity will be eventually established and the cross-sectional shrinkage distribution will have uniform values. The internal relative humidity distribution of GI-5 and GII-1 achieves the equilibriums in shorter time as compared with GIII-5, since the effective diffusion coefficient $\left(D_{0}\right.$ and $\left.D_{1}\right)$ of GIII-5 is much lower. As a result, the cross-sectional shrinkage distribution in GIII-5 also takes longer time to reach the uniform value (Figure 10). Nevertheless, the actual cross-sectional shrinkage distributions could be complicated by the internal creep. Self-equilibrium internal stresses can develop 
in the specimens due to the material inhomogeneities and nonuniform strain distribution. Hence, even without the application of external loading, the internal stresses can induce internal creep, which can be coupled with the free shrinkage as given by Figure 10b-d. Yet, this secondary effect is normally relatively minor and hence ignored by most shrinkage models for concrete (e.g. [23]).

\section{Scaled-up in field test}

GIII-5 was scaled-up in a full scale twin-screw mixer of a concrete production plant. In the previous laboratory study, the rheology was determined empirically so that the target density in the range of $1500-1700 \mathrm{~kg} / \mathrm{m}^{3}$ could be fabricated without segregation and excessive bleeding consistently. Also, the setting time was tuned to be around 60-75 minutes. The main objective was to verify the scalability of the low drying shrinkage formulation developed in laboratory. A full scale reinforced foamed concrete slab was made (Figure 11). The dimensions of the slab were $2.9 \mathrm{~m} \times 2.5 \mathrm{~m} \times 0.15 \mathrm{~m}$. There were two layers of T10 steel reinforcing mesh with $250 \mathrm{~mm}$ centre-to-centre spacing. The concrete cover was $30 \mathrm{~mm}$.

The foamed concrete was made by preformed foam. The targeted wet density was $1,600 \mathrm{~kg} / \mathrm{m}^{3}$. After mixing all dry powder in the mixer for 1 minute, water and superplasticiser was added. The wet mix was continuously mixed for another 1 minute. The wet mix was poured into a concrete truck for continuous mixing. The preformed foam was pumped from the output of a home-made foam generator from the concrete producer directly into the concrete truck barrel. The amount of foam added was determined 
by the targeted density and the duration of foam pumping. The rate of foam generated was calibrated in terms of flow rate $\left(\mathrm{m}^{3} / \mathrm{s}\right)$. The foamed concrete was poured into $100 \mathrm{~mm}$ cubes to measure the wet density immediately on-site. The averaged wet density of three samples was $1720 \mathrm{~kg} / \mathrm{m}^{3}$. The averaged 28th day compressive strength of three cubic samples cured in standard condition was $29.2 \mathrm{MPa}$. Three $40 \mathrm{~mm} \times 40 \mathrm{~mm} \times 300 \mathrm{~mm}$ prisms were cast for drying shrinkage measurement. There were three more sets of prisms without foaming based on the common strategies of the concrete producer to reduce drying shrinkage by using gypsum dihydrate $\left(C \bar{S} H_{2}\right)$ and gypsum anhydrite $(C \bar{S})$. The binder (OPC, CSA-blend and GGBS) of GIII5 was replaced by (i) $90 \% \mathrm{OPC}+10 \% C \bar{S} H_{2}$, (ii) $90 \% \mathrm{OPC}+10 \% C \bar{S}$ and (iii) $90 \% \mathrm{OPC}+5 \% C \bar{S}+5 \% C \bar{S} H_{2}$. There was $20 \% \mathrm{LF}$ of the total mass of all powder. The dosage of SP, SF and HPMC was the same as the previous study. The water to powder ratio was kept at 0.285 .

The slab was exposed in ambient semi-outdoor environment with canopy to prevent direct exposure to rainfall and sun radiation without temperature regulation. The location of field test was in Shunde, Guangdong province of China. The slab was fabricated in late January 2016. In the 193-day of field test, the average, minimum and maximum temperature was $18^{\circ} \mathrm{C}, 0^{\circ} \mathrm{C}$ and $37^{\circ} \mathrm{C}$, respectively. After 193 days of field test, there was no visible suspicious drying shrinkage crack. The 4 sets of prisms were exposed to the same environment with the slab. The summary of the drying shrinkage after 193 days from casting in the field test is shown in Table 7. The drying shrinkage of foamed GIII-5 was much lower compared to the common strategies of reducing drying shrinkage of the concrete producer and it was much smaller 
in actual ambient environment than the more severer artificial environmental in laboratory.

\section{Simulation of full scale panels by FE model with hygro-mechanical model}

\subsection{Model development}

The potential crack developments of three prototypes of reinforced concrete panels (Figure 12), made of GI-5, GII-1 or GIII-5, are studied by FE simulations using the calibrated hygro-mechanical models in section 5 . The panels have the same height and thickness of $2.9 \mathrm{~m}$ and $0.15 \mathrm{~m}$, respectively. The horizontal widths of Type I, Type II and Type III panels are $1 \mathrm{~m}, 2 \mathrm{~m}$ and $2 \mathrm{~m}$ respectively. Type III panel has a window-opening with sizes of $1.2 \mathrm{~m} \times 1.5 \mathrm{~m}$. There are two layers of reinforcement mesh of T10 steel with approximate $250 \mathrm{~mm}$ centre-to-centre spacing. The material models and meshing for concrete are similar to those in section 5. The reinforcement mesh is modelled by truss elements with the same meshing size as the solid elements of concrete. The steel reinforcement is assumed to be impermeable to moisture. The elastic modulus and Poisson's ratio of steel is $200 \mathrm{GPa}$ and 0.3 , respectively. The environmental exposure conditions of the panels are defined to be constant relative humidity of $55 \%$ and temperature of $23^{\circ} \mathrm{C}$ for 90 days.

\subsection{Simulation results and discussion}

As an illustration, the 90th day crack pattern, principal strain directions and von Mises distribution in steel reinforcement mesh the GI-5 panel on the 
mid-plane are shown in Figure 13. The equivalent crack width $\omega$ is calculated by Eq. (29).

$$
\omega=\ell_{e q} \cdot \varepsilon_{1}^{p}
$$

where $\varepsilon_{1}^{p}$ is the major principal inelastic strain. In the developed ABAQUS subroutine, the equivalent crack width at each integration point is stored as the state variable SDV19.

Figure 13a shows the contour plots of the equivalent crack width distributions of the three panels. The corresponding crack opening directions are depicted by the maximum principal strain directions as shown in Figure 13b. The corner regions of the panels have the fastest rate of moisture loss and the resulted drying shrinkage is also the largest in those regions. The shrinkage is then restrained by the steel reinforcement and tensile stress will continue to develop until the tensile strength of concrete is exceeded. As a result, the major cracks start to propagate from near the corners to the mid-points between two adjacent corners, forming a closed loop of crack path denoted as the loop C as shown in Figure 13. For Type III panel with a window opening, another closed crack path is formed around the window opening but with the smaller crack width compared with that of the outer crack path. As shown in Figure 13, the stress in the reinforcement near the cracked regions is also lower than that in the inner regions with minor or no cracking. Besides the maximum crack width, the average crack width along the major crack path C is evaluated in Eq. (30).

$$
\omega_{c}=\frac{1}{L_{c}} \oint_{c} \omega \cdot d \ell
$$

where $L_{c}$ is the perimeter of the loop C. 
Evolutions of the maximum crack widths near the corner regions and the average crack width along the perimeter of the loop $\mathrm{C}$ are plotted against the days of curing as shown in Figure 14. It can be seen that the maximum and average crack widths developed in all three types of panel have similar values, but the Type II panel has the largest cracks on the 90th day. The maximum crack widths developed in the Type II panel after 90 days are $0.1579 \mathrm{~mm}, 0.2117 \mathrm{~mm}$, and $0.0666 \mathrm{~mm}$ for GI-5, GII-1, and GIII-5 respectively, and the corresponding average crack widths on the 90th day are $0.1275 \mathrm{~mm}, 0.1721 \mathrm{~mm}$, and $0.054 \mathrm{~mm}$ respectively. The regression relationships between the free shrinkage and crack width development are shown in Figure 14d. Although the shrinkage crack opening from simulation is smaller than typical threshold of $0.3 \mathrm{~mm}$, it may be exacerbated by thermal and mechanical effects which have not been considered in the simulations but the FE model can be extended to incorporate the mechanical, thermal and time dependent effect on the crack potential based on the hygro-mechanical model and incremental stress-strain constitutive relationship. Furthermore, early corrosion of the reinforcement in the $\mathrm{RC}$ panels can occur if the crack width reaches more than $0.2 \mathrm{~mm}$ after 90 days of curing. Therefore, GIII-5, which has the smallest crack width of less than $0.1 \mathrm{~mm}$ in the simulations, is suggested for the fabrication of foamed concrete façades.

\section{Conclusions}

In this paper, the benefits of using lightweight prefabricated permanent formwork was discussed. The verification test showed that the drying shrinkage of foamed concrete in the density range around $1,500 \mathrm{~kg} / \mathrm{m}^{3}$ could be 
approximated by the non-foamed counterpart. Three different strategies of reducing drying shrinkage were investigated. The OPC-GGBS blend and MEA showed excessive drying shrinkage $(>2,000 \mu \varepsilon)$. The CSA-blend could significantly reduce the drying shrinkage. The formulation developed in laboratory was successfully verified by fabricating a full scale reinforced foamed concrete in a field test. The drying shrinkage of the developed formulation in the field test was significantly smaller than the standard environment in laboratory. It was also superior to the conventional strategies of concrete producer by using anhydrite or dihydrate to reduce drying shrinkage of OPC.

A hygro-mechanical model was developed to consider the diffusion of moisture, shrinkage and plastic strain evolution. The incremental stressstrain constitutive relationship of the model was derived and it could be incorporated in general FE routine. The model was calibrated by the results of drying shrinkage test in this study. The simulation demonstrated how cracking potential could be examined and it could help the engineers to model the crack formation potential with the consideration of mechanical, thermal, time-dependent and other possible factors in general FE routine.

\section{Acknowledgement}

The work of this paper is sponsored by CC003/12 from Nano and Advanced Materials Institute Limited, Hong Kong and Global Challenges Research Fund of Engineering and Physical Sciences Research Council, UK (EP/P510749/1/R33466/R33471). Thank you for the technical support from the Housing Department of the government of Hong Kong SAR, Gammon Construction Limited and Quon Hing Concrete Company Limited. 


\section{References}

[1] Al-Khaiat, H., Haque, M. N., 1998. Effect of initial curing on early strength and physical properties of a lightweight concrete. Cement and Concrete Research 28 (6), 859-866.

[2] Ardeshirilajimi, A., Wu, D., Chaunsali, P., Mondal, P., 2017. Effects of presoaked lightweight aggregate on deformation properties of ordinary Portland cement-calcium sulfoaluminate cement blends. ACI Materials Journal 114 (4), 643-652.

[3] Basri, H. B., Mannan, M. A., Zain, M. F. M., 1999. Concrete using waste oil palm shells as aggregate. Cement and Concrete Research 29 (4), 619622.

[4] Bazant, Z., Baweja, S., 1996. Creep and shrinkage prediction model for analysis and design of concrete structures-model B3. Materials and Structures 29, doi: 10.1007/BF02486204.

[5] Beltzung, F., Wittmann, F., 2005. Role of disjoining pressure in cement based materials. Cement and Concrete Research 35, doi: 10.1016/j.cemconres.2005.04.004.

[6] Berodier, E., Scrivener, K., 2015. Evolution of pore structure in blended systems. Cement and Concrete Research 73, 25-35.

[7] British-Standard-Institution, 2005. Determination of setting times and soundness. BS EN 196-3:2005+A1:2008, Methods of testing cement, 118. 
[8] British-Standard-Institution, 2009. Determination of drying shrinkage of concrete for samples prepared in the field or in the laboratory. BS ISO 1920-8:2009, Testing of concrete, 1-26.

[9] Brue, F. N. G., Davy, C. A., Burlion, N., Skoczylas, F., Bourbon, X., 2017. Five year drying of high performance concretes: Effect of temperature and cement-type on shrinkage. Cement and Concrete Research 99, $70-85$.

[10] Cau Dit Coumes, C., Dhoury, M., Champenois, J.-B., Mercier, C., Damidot, D., 2017. Combined effects of lithium and borate ions on the hydration of calcium sulfoaluminate cement. Cement and Concrete Research $97,50-60$.

[11] CEB-FIP, 2012. Model Code 2010 - Final version. fib Bull 65Federation Int du Beton 1, doi: 10.1007/s13398-014-0173-7.2.

[12] Chaunsali, P., Mondal, P., 2016. Hydration and early-age expansion of calcium sulfoaluminate cement-based binders: experiments and thermodynamic modeling. Journal of Sustainable Cement-Based Materials 5 (4), 259-267.

[13] Chen, W., 1982. Plasticity in Reinforced Concrete. McGraw-Hill.

[14] Cho, K., Shin, Y.-S., Kim, T., 2017. Effects of half-precast concrete slab system on construction productivity. Sustainability (Switzerland) 9 (7).

[15] den Engelsen, C. W., Isarin, J. C., Gooijer, H., Warmoeskerken, M. M. C. G., Wassink, J. G., 2002. Bubble size distribution of foam. Autex Research Journal 2 (1), 14-27. 
[16] Dong, Y. H., Ng, S. T., 2015. A life cycle assessment model for evaluating the environmental impacts of building construction in Hong Kong. Building and Environment 89, 183-191.

[17] Du, L., Folliard, K. J., 2005. Mechanisms of air entrainment in concrete. Cement and Concrete Research 35 (8), 1463-1471.

[18] (ed) Bazant, Z. (Ed.), 1988. Mathematical Modelling of Creep and Shrinkage of Concrete. RILEM Committee TC-69. John Wiley \& Sons.

[19] Gao, P., Lu, X., Geng, F., Li, X., Hou, J., Lin, H., Shi, N., 2008. Production of $\mathrm{MgO}$-type expansive agent in dam concrete by use of industrial by-products. Building and Environment 43 (4), 453-457.

[20] Gesoglu, M., Özturan, T., Güneyisi, E., 2004. Shrinkage cracking of lightweight concrete made with cold-bonded fly ash aggregates. Cement and Concrete Research 34 (7), 1121-1130.

[21] Glasser, F. P., Zhang, L., 2001. High-performance cement matrices based on calcium sulfoaluminate-belite compositions. Cement and Concrete Research 31 (12), 1881-1886.

[22] Grasley, Z., Lange, D., D’Ambrosia, M., 2006. Internal relative humidity and drying stress gradients in concrete. Materials and Structures 39, doi: 10.1617/s11527-006-9090-3.

[23] Idiart, A., 2009. Coupled analysis of degradation processes in concrete specimens at the meso-level. Ph.D. thesis, Universitat Politècnica de Catalunya. 
[24] Inc, A., 2014. Abaqus User Subroutines Reference Guide. ABAQUS Inc.

[25] Jennings, H., 2008. Refinements to colloid model of C-S-H in cement: CM-II. Cement and Concrete Research 38, doi: 10.1016/j.cemconres.2007.10.006.

[26] Jennings, H., Kumar, A., Sant, G., 2015. Quantitative discrimination of the nano-pore-structure of cement paste during drying: New insights from water sorption isotherms. Cement and Concrete Research 76, doi: 10.1016/j.cemconres.2015.05.006.

[27] Jeong, Y., Hargis, C. W., Chun, S., Moon, J., 2017. Effect of calcium carbonate fineness on calcium sulfoaluminate-belite cement. Materials $10(8)$.

[28] Just, A., Middendorf, B., 2009. Microstructure of high-strength foam concrete. Materials Characterization 60 (7), 741-748.

[29] Kayali, O., Haque, M. N., Zhu, B., 1999. Drying shrinkage of fibrereinforced lightweight aggregate concrete containing fly ash. Cement and Concrete Research 29 (11), 1835-1840.

[30] Kearsley, E., Wainwright, P., 2002. The effect of porosity on the strength of foamed concrete. Cement and Concrete Research 32 (2), 233-239.

[31] Kim, T., Chae, C., 2016. Evaluation analysis of the COjinf ¿2i/inf sion and absorption life cycle for precast concrete in Korea. Sustainability (Switzerland) 8 (7). 
[32] Kleiman, S., Chaim, R., 2007. Thermal stability of MgO nanoparticles. Materials Letters 61 (23-24), 4489-4491.

[33] Krätzig, W., Pölling, R., 2004. An elasto-plastic damage model for reinforced concrete with minimum number of material parameters. Computer \& Structures 82, doi: 10.1016/j.compstruc.2004.03.002.

[34] Kumar, A., Oey, T., Falzone, G., Huang, J., Bauchy, M., Balonis, M., Neithalath, N., Bullard, J., Sant, G., 2017. The filler effect: The influence of filler content and type on the hydration rate of tricalcium silicate. Journal of the American Ceramic Society 100 (7), 3316-3328.

[35] Kurama, H., Topçu, I. B., Karakurt, C., 2009. Properties of the autoclaved aerated concrete produced from coal bottom ash. Journal of Materials Processing Technology 209 (2), 767-773.

[36] Lan, W., Glasser, F. P., 1996. Hydration of calcium sulphoaluminate cements. Advances in Cement Research 8 (31), 127-134.

[37] Lee, C., Lange, D., Liu, Y., 2011. Prediction of moisture curling of concrete slab. Materials and Structures 44, doi: 10.1617/s11527-0109665-x.

[38] Li, C., 1999. Long term study on autogenous deformation of concrete added with $\mathrm{MgO}$. Sichuan Water Power 18, 68-72.

[39] Liu, M. Y. J., Alengaram, U. J., Jumaat, M. Z., Mo, K. H., 2014. Evaluation of thermal conductivity, mechanical and transport properties of lightweight aggregate foamed geopolymer concrete. Energy and Buildings $72,238-245$. 
[40] Maruyama, I., 2010. Origin of drying shrinkage of hardened cement paste: Hydration pressure. Journal of Advanced Concrete Technology 8 (2), 187-200.

[41] Mejias, J. A., Berry, A. J., Refson, K., Fraser, D. G., 1999. The kinetics and mechanism of $\mathrm{MgO}$ dissolution. Chemical Physics Letters 314 (5-6), $558-563$.

[42] Mo, L., Deng, M., Tang, M., Al-Tabbaa, A., 2014. MgO expansive cement and concrete in China: Past, present and future. Cement and Concrete Research 57, 1-12.

[43] Narayanan, N., Ramamurthy, K., 2000. Structure and properties of aerated concrete: A review. Cement and Concrete Composites 22 (5), 321329.

[44] Ottosen, N., 1977. A Failure Criterion for Concrete. Journal of Engineering Mechanics ASCE 103.

[45] Péra, J., Ambroise, J., 2004. New applications of calcium sulfoaluminate cement. Cement and Concrete Research 34 (4), 671-676.

[46] Pinson, M., Jennings, H., Bazant, M., 2014. Inferring Pore Size and Network Structure from Sorption Hysteresis. arXiv.

[47] Sanjayan, J. G., Nazari, A., Chen, L., Nguyen, G. H., 2015. Physical and mechanical properties of lightweight aerated geopolymer. Construction and Building Materials 79, 236-244. 
[48] Shariq, M., Prasad, J., Abbas, H., 2016. Creep and drying shrinkage of concrete containing GGBFS. Cement and Concrete Composites 68, $35-45$.

[49] Sloan, S., Abbo, A., Sheng, D., 2001. Refined explicit integration of elastoplastic models with automatic error control. Engineering Computations 18, doi: 10.1108/02644400110365842.

[50] Tang, S. W., Zhu, H. G., Li, Z. J., Chen, E., Shao, H. Y., 2015. Hydration stage identification and phase transformation of calcium sulfoaluminate cement at early age. Construction and Building Materials 75, $11-18$.

[51] Topçu, I. B., Uygunoğlu, T., 2007. Properties of autoclaved lightweight aggregate concrete. Building and Environment 42 (12), 4108-4116.

[52] Valore, R., 1954. Cellular concretes-composition and methods of preparation. Journal of American Concrete Institute 25, 773-795.

[53] Valore, R., 1954. Cellular concretes-physical properties. Journal American Concrete Institute 25, 817-836.

[54] Weigler, H., Karl, S., 1980. Structural lightweight aggregate concrete with reduced density- lightweight aggregate foamed concrete. International Journal of Cement Composites and Lightweight Concrete 2 (2), 101-104.

[55] Winnefeld, F., Lothenbach, B., 2010. Hydration of calcium sulfoaluminate cements - Experimental findings and thermodynamic modelling. Cement and Concrete Research 40 (8), 1239-1247. 
[56] Wittmann, F., 1968. Surface tension skrinkage and strength of hardened cement paste. Materials and Structures 1, doi: 10.1007/BF02473643.

[57] Yang, K., Lee, K., Song, J., Gong, M., 2014. Properties and sustainability of alkali-activated slag foamed concrete. Journal of Cleaner Production 68, 226-233.

[58] Ye, H., Radlińska, A., 2016. A Review and Comparative Study of Existing Shrinkage Prediction Models for Portland and Non-Portland Cementitious Materials. Advances in Materials Science and Engineering 2016 .

[59] Zhang, Z., Provis, J., Reid, A., Wang, H., 2014. Geopolymer foam concrete: An emerging material for sustainable construction. Construction and Building Materials 56, 113-127.

[60] Ziembicka, H., 1977. Effect of micropore structure on cellular concrete shrinkage. Cement and Concrete Research 7 (3), 323-332. 


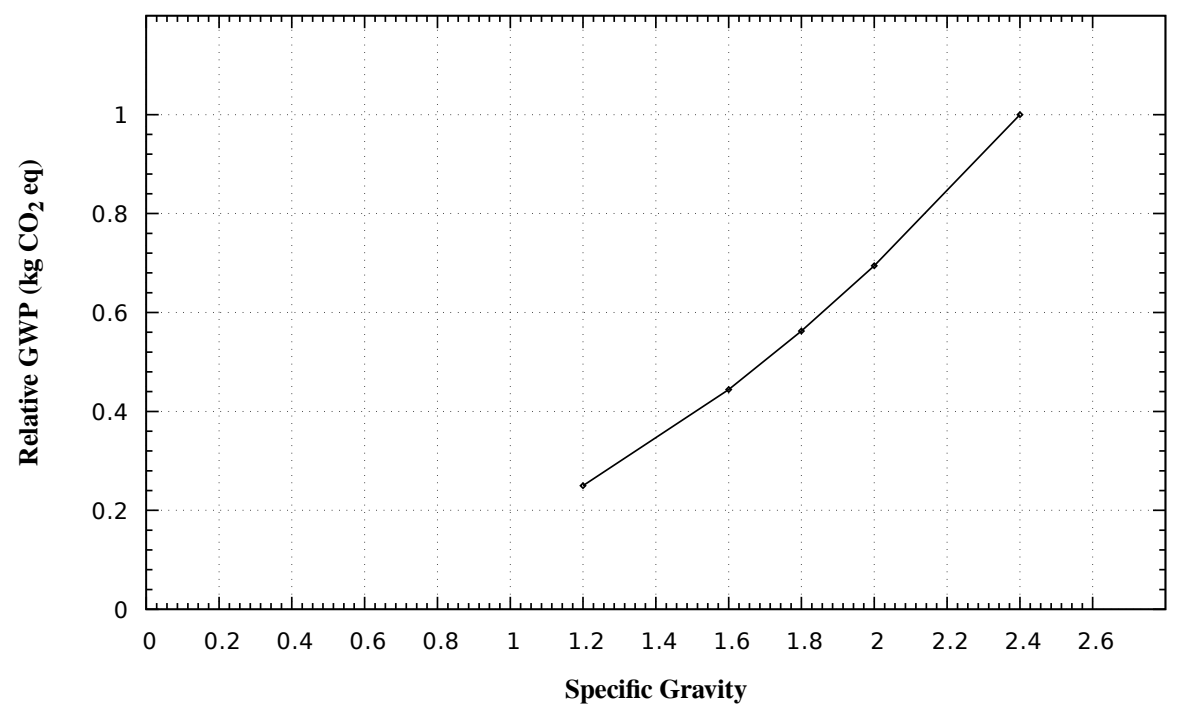

Figure 1: Relative global warming potential (GWP) by lorry transport for $200 \mathrm{~km}$ with different density of 12 full scale building fasçades. 

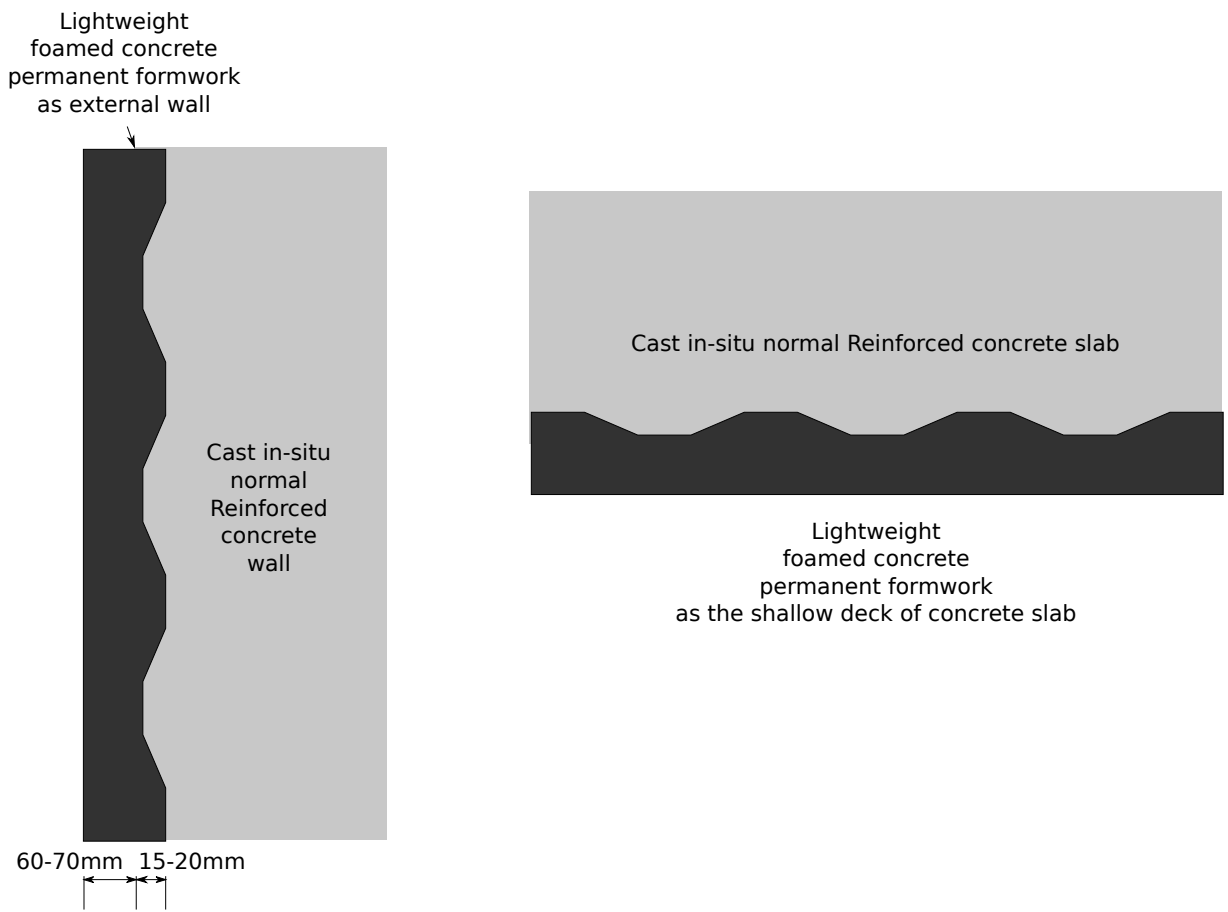

Figure 2: Typical sandwich structure of prefabricated reinforced concrete panel with enhanced thermal insulation. (a) structural wall and (b) floor slab. 


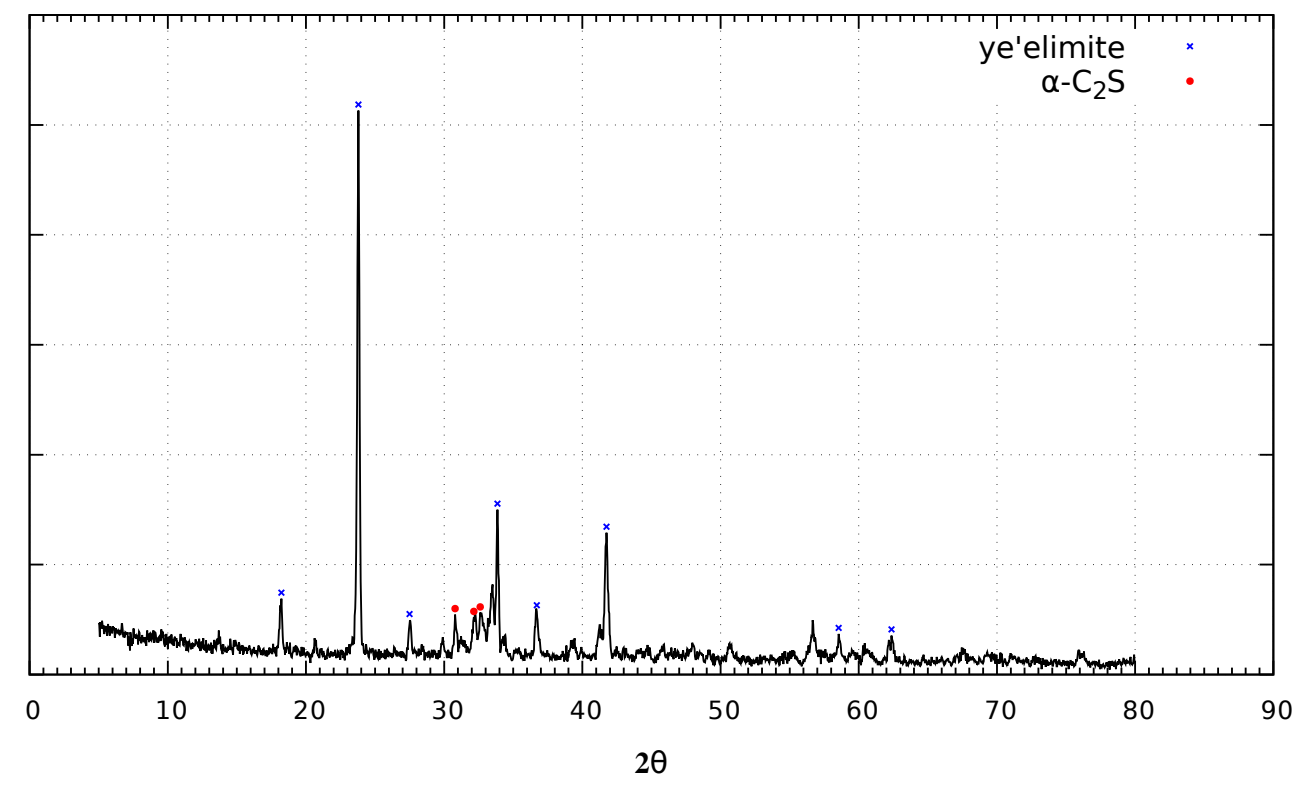

Figure 3: XRD pattern of the as-received CSA cement clinker. 


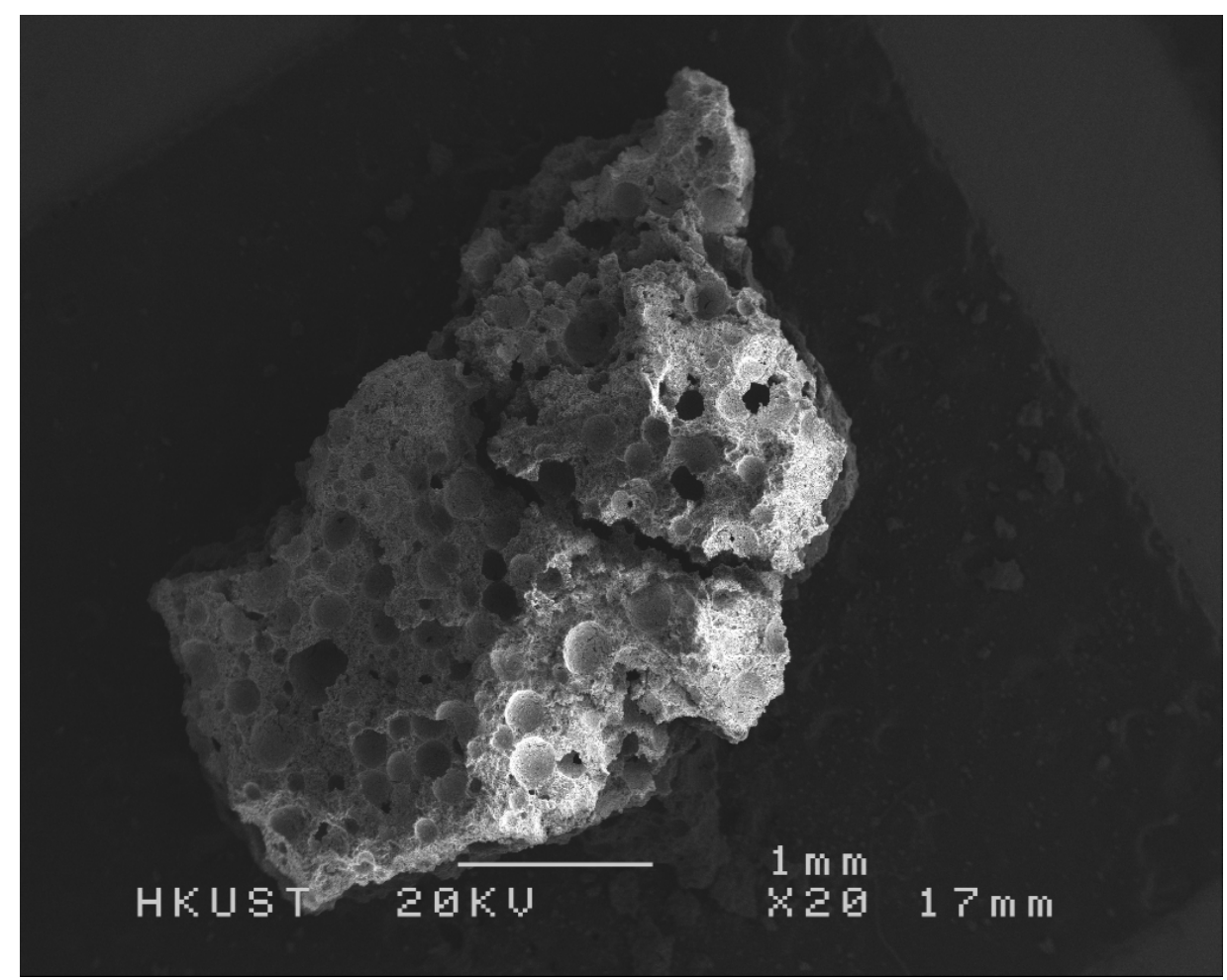

(a) $20 \mathrm{X}$

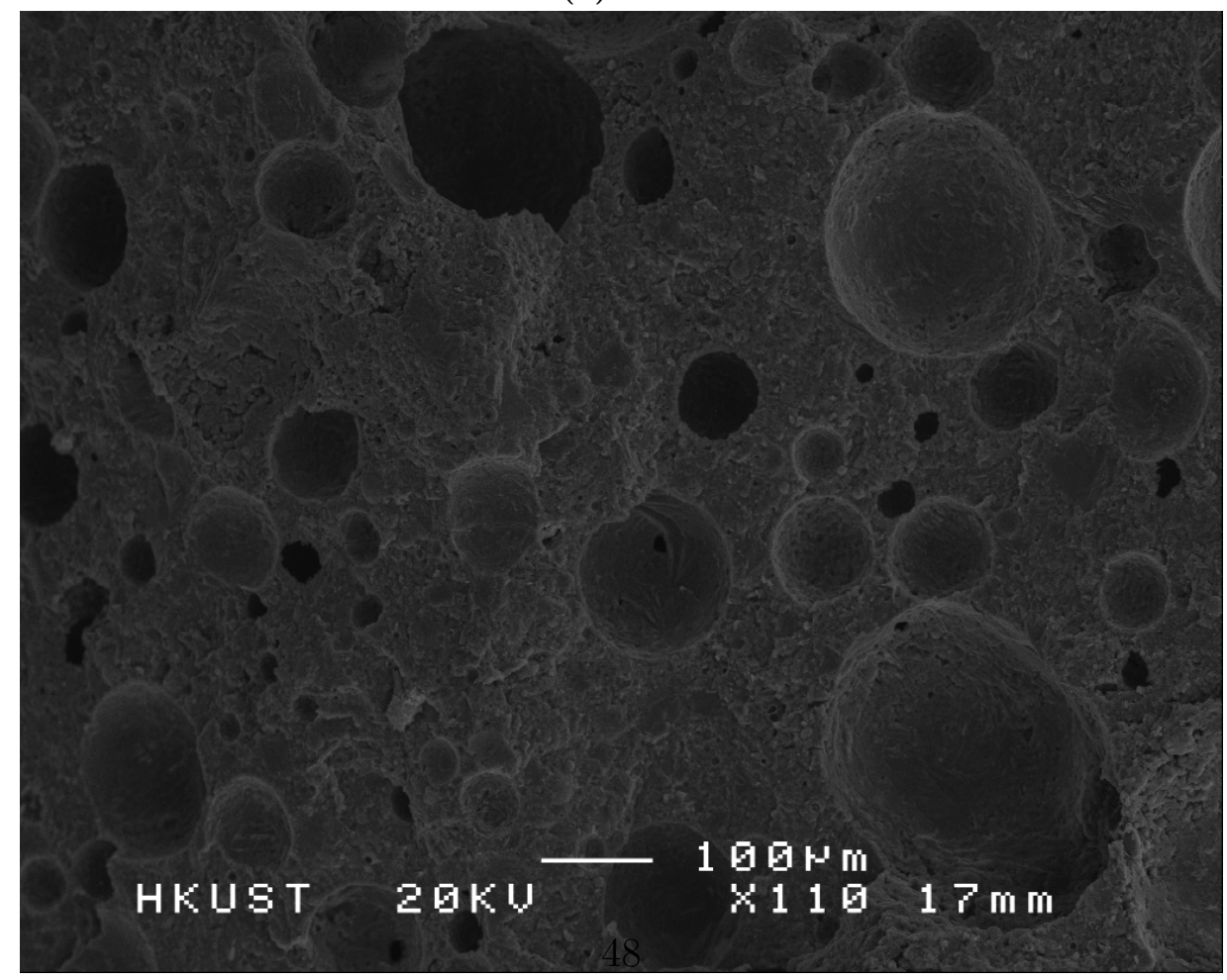

(b) $110 \mathrm{X}$

Figure 4: Micrograph of foamed concrete of wet density about $1,500 \mathrm{~kg} / \mathrm{m}^{3}$. 


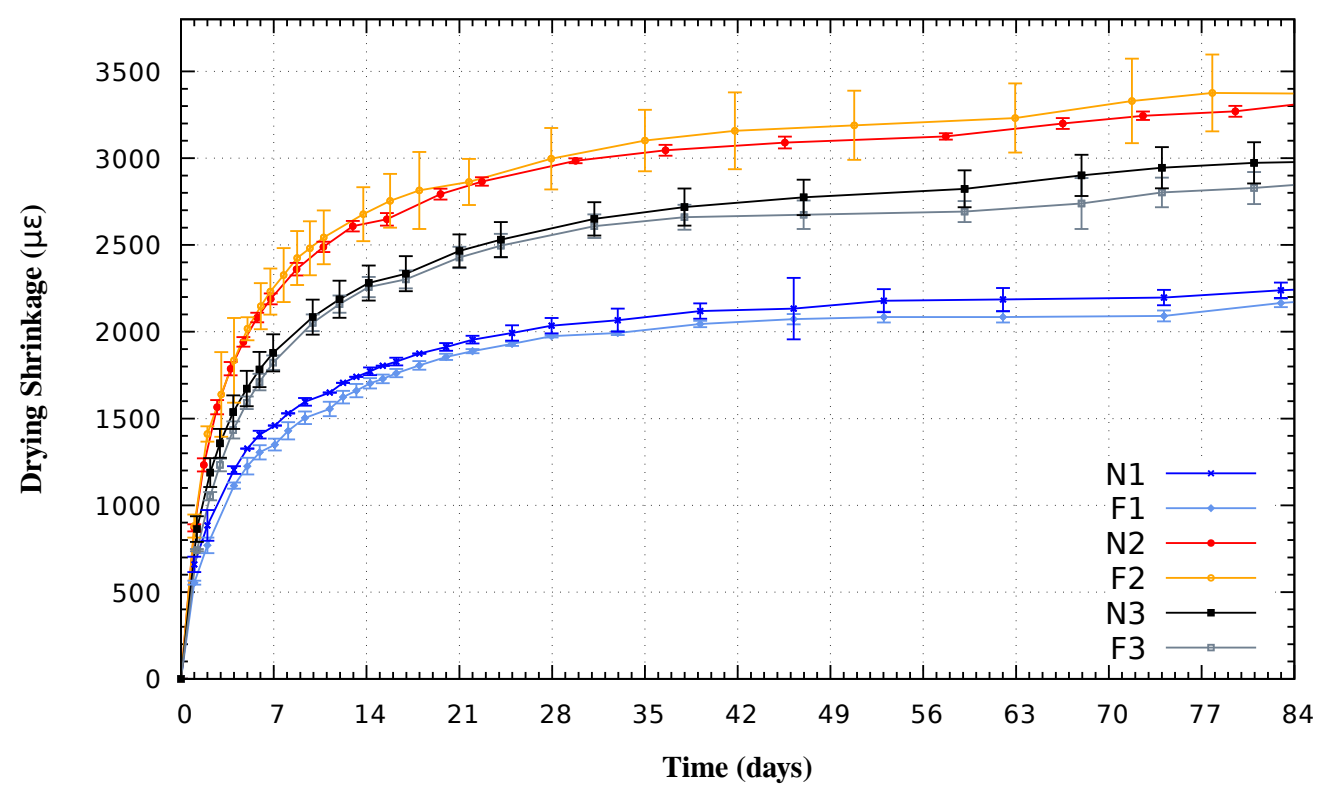

(a) Verification test

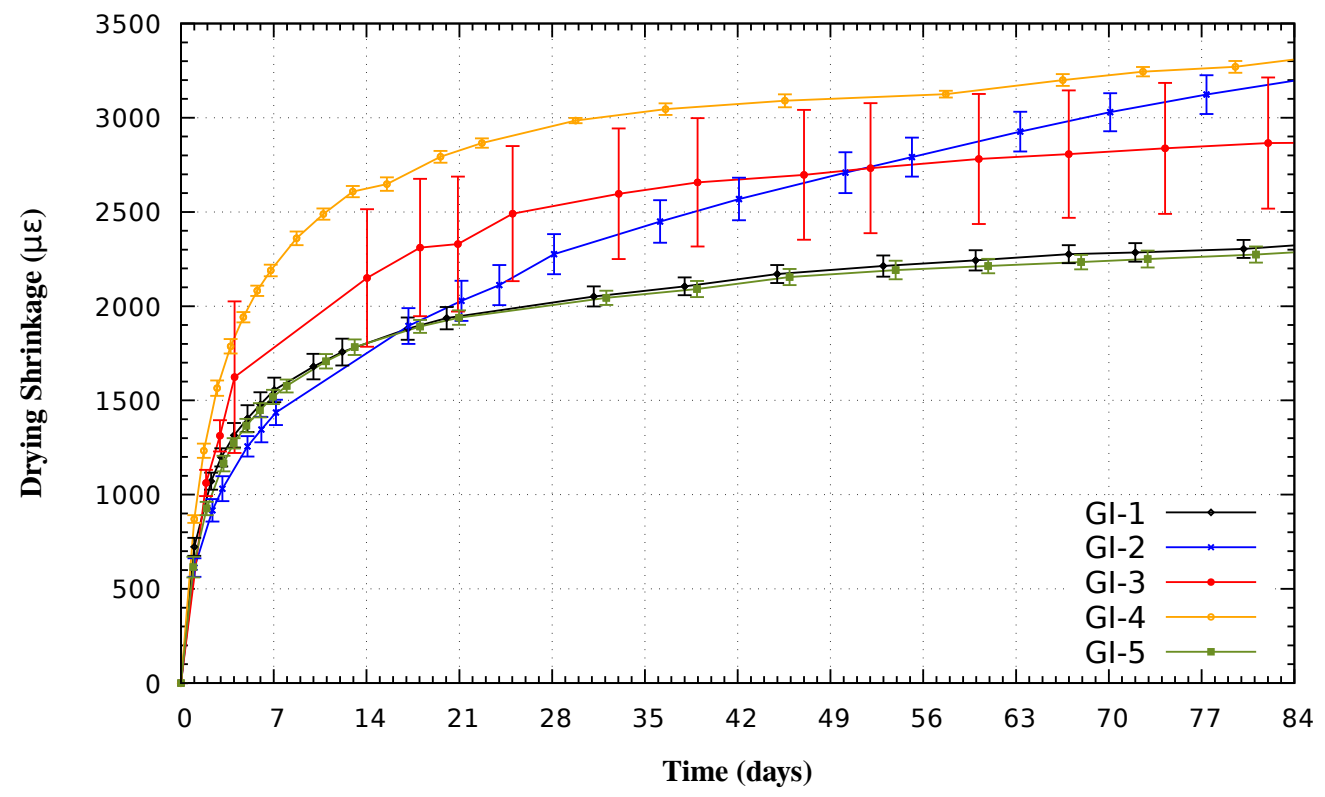

(b) GI 


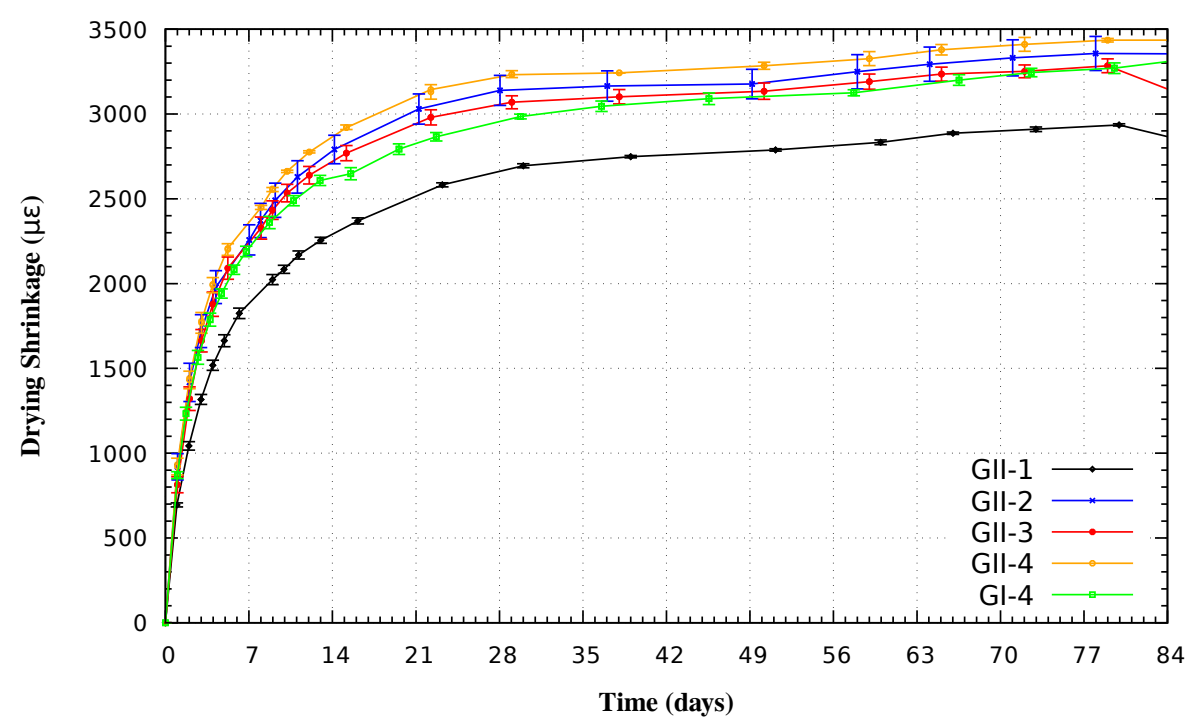

(c) GII

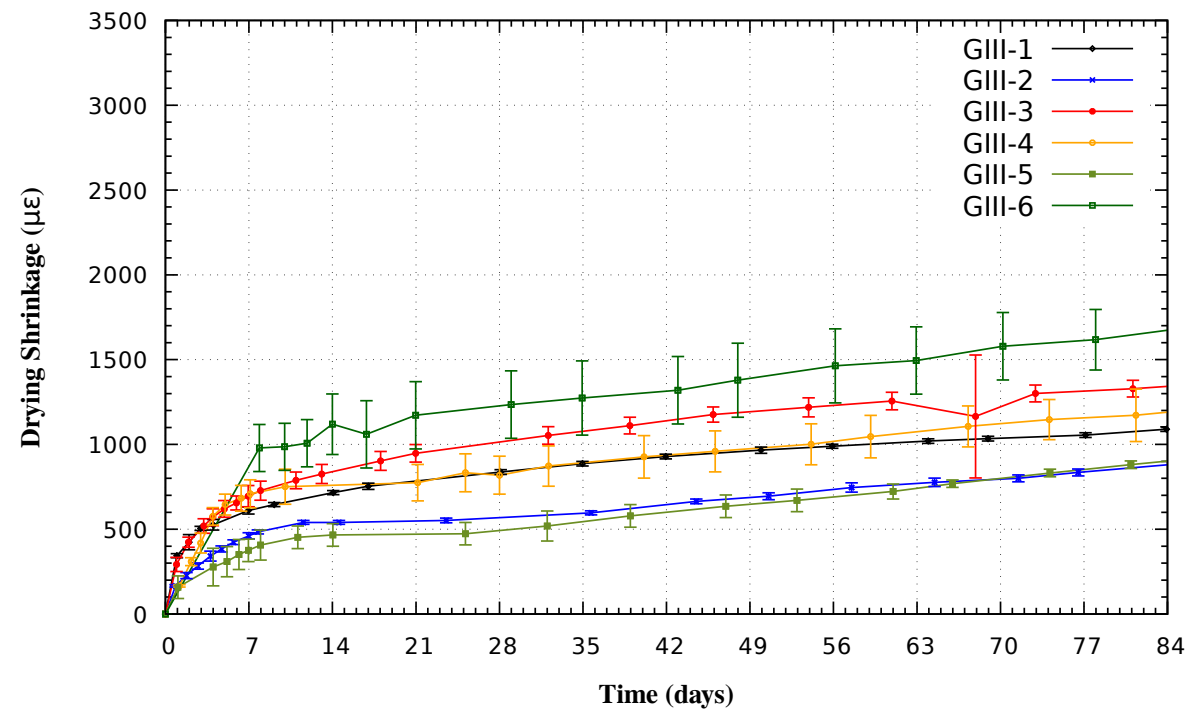

(d) GIII

Figure 5: Results of drying shrinkage test. 


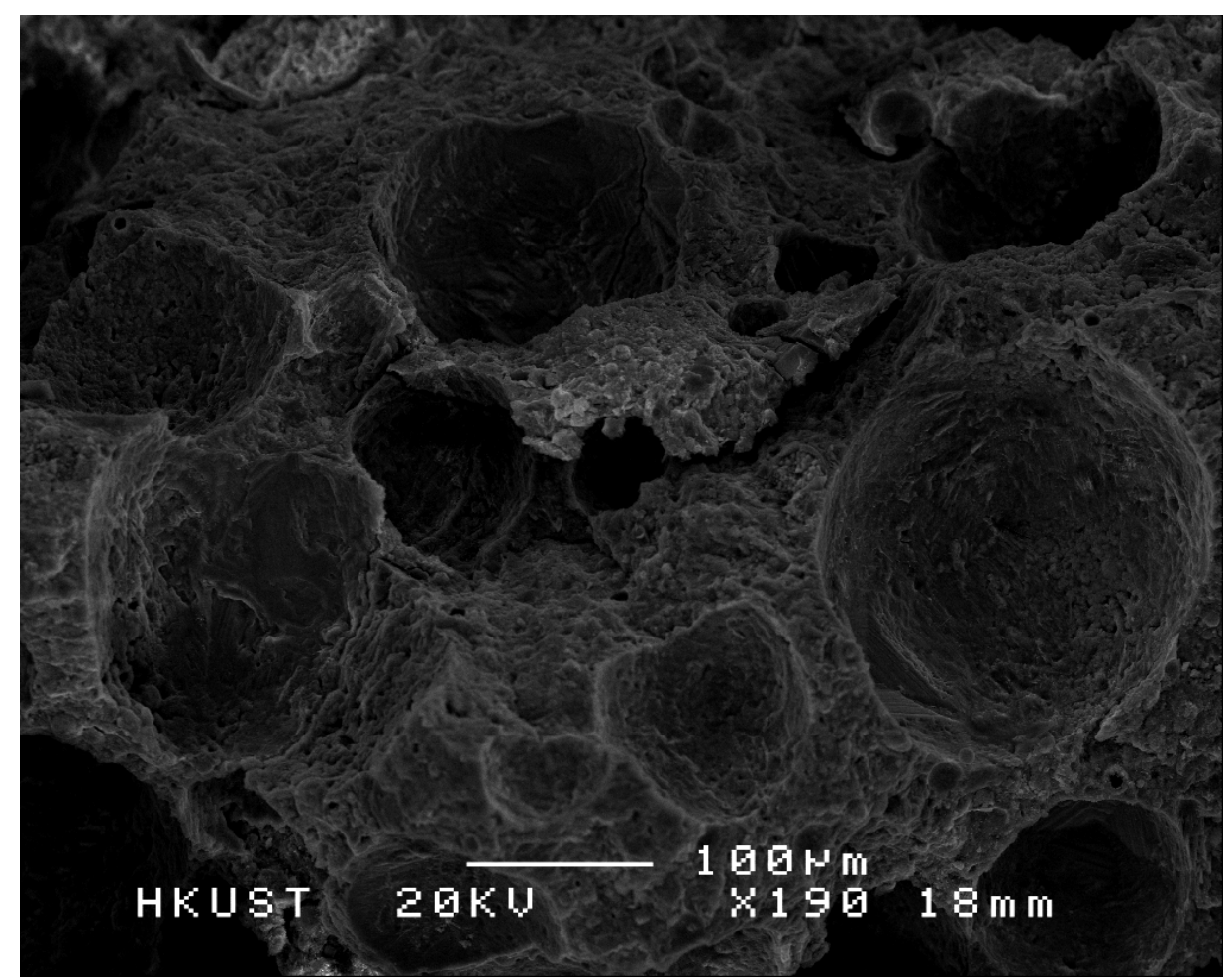

(a)

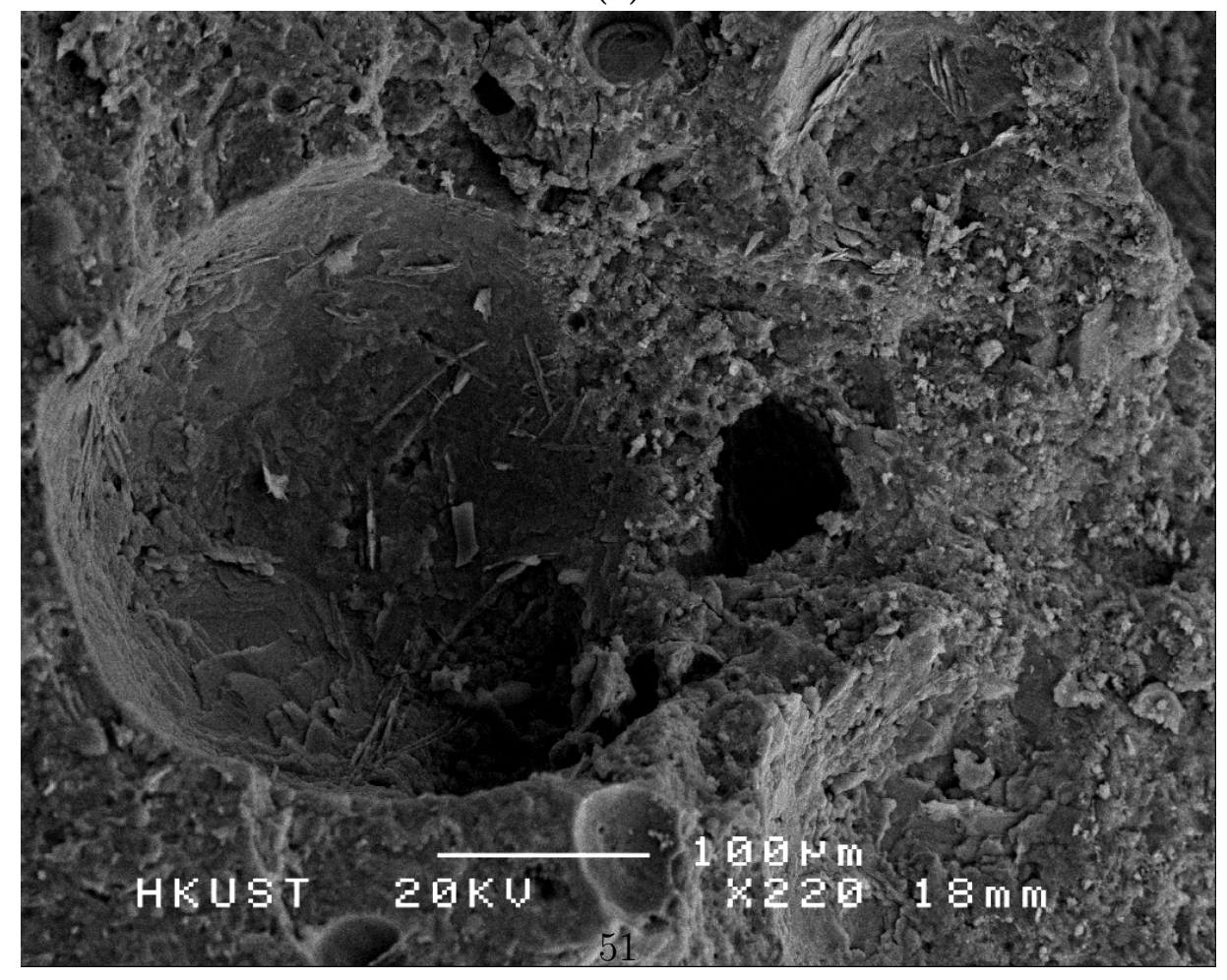

(b)

Figure 6: Micrographs of (a) foamed GIII-4 and (b) foamed GIII-5. 


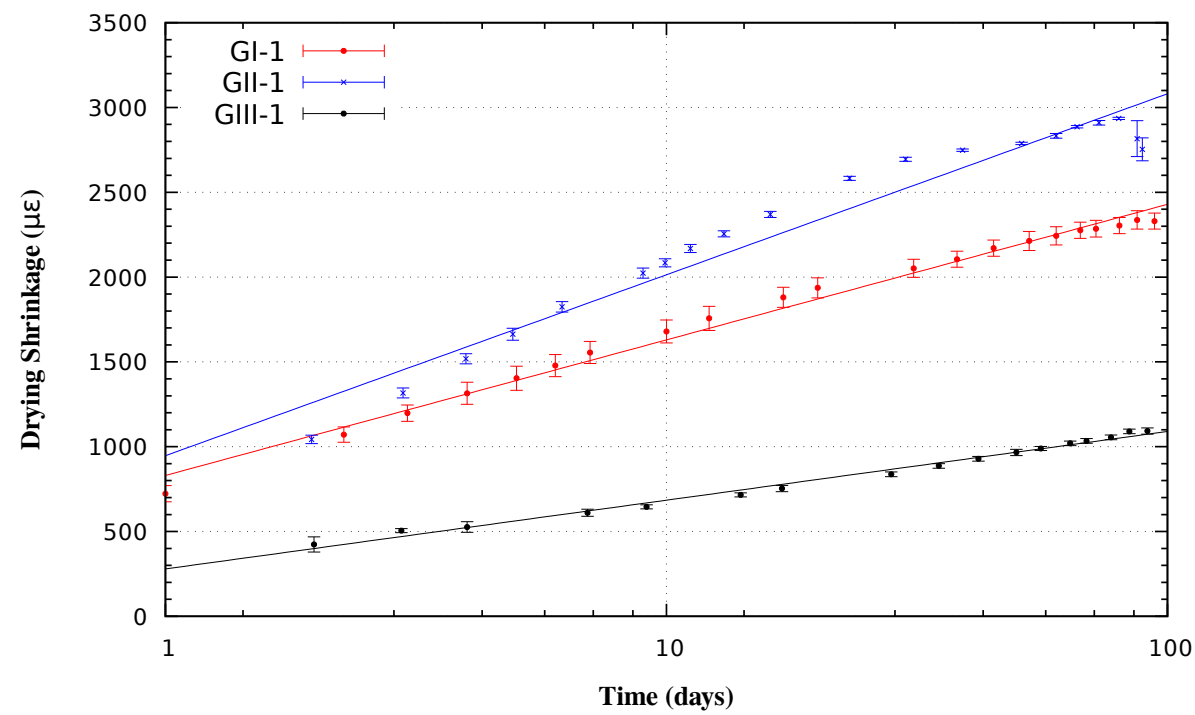

Figure 7: Semi-log plot of typical results of drying shrinkage test and the best-fitted lines. 


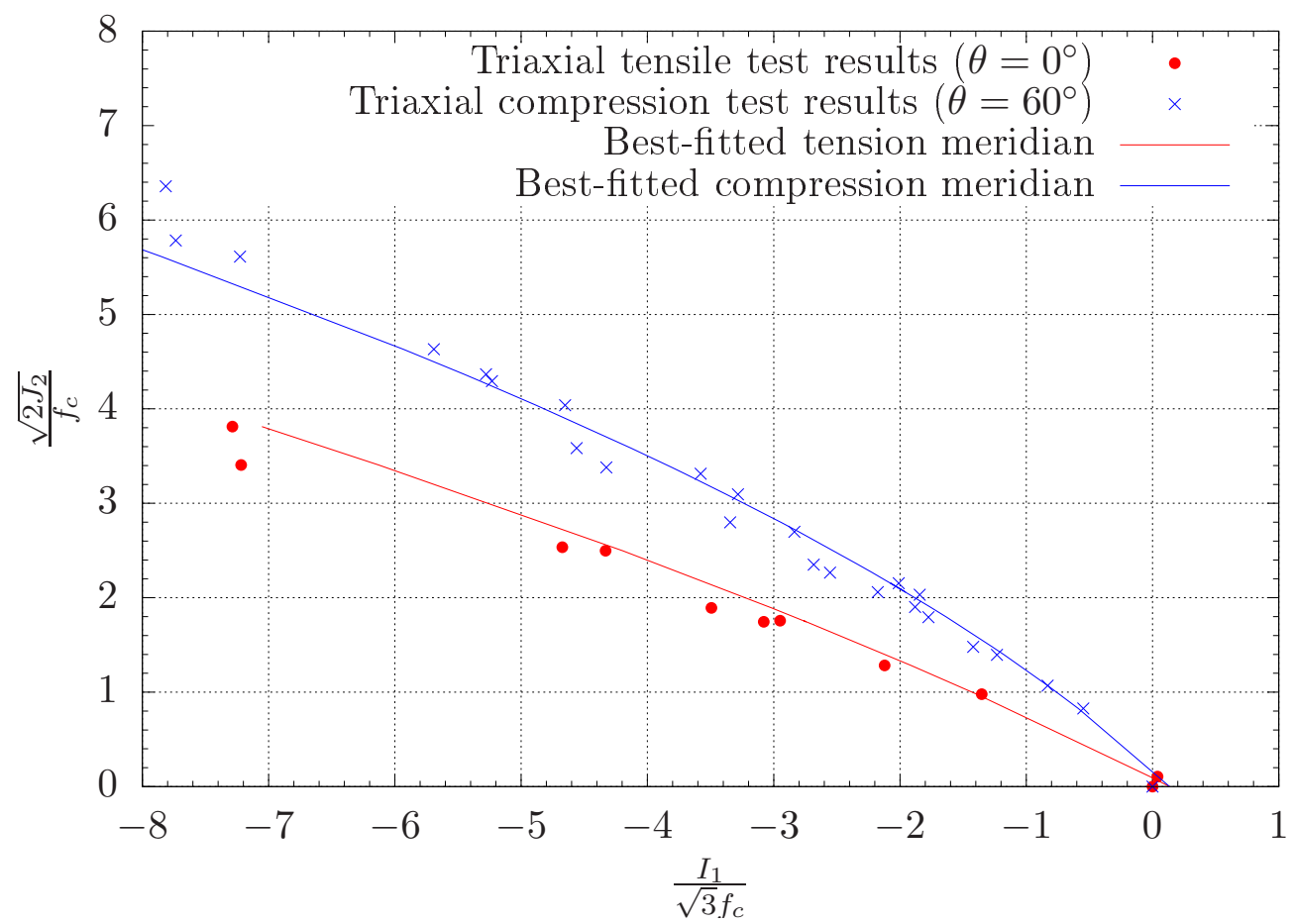

(a)

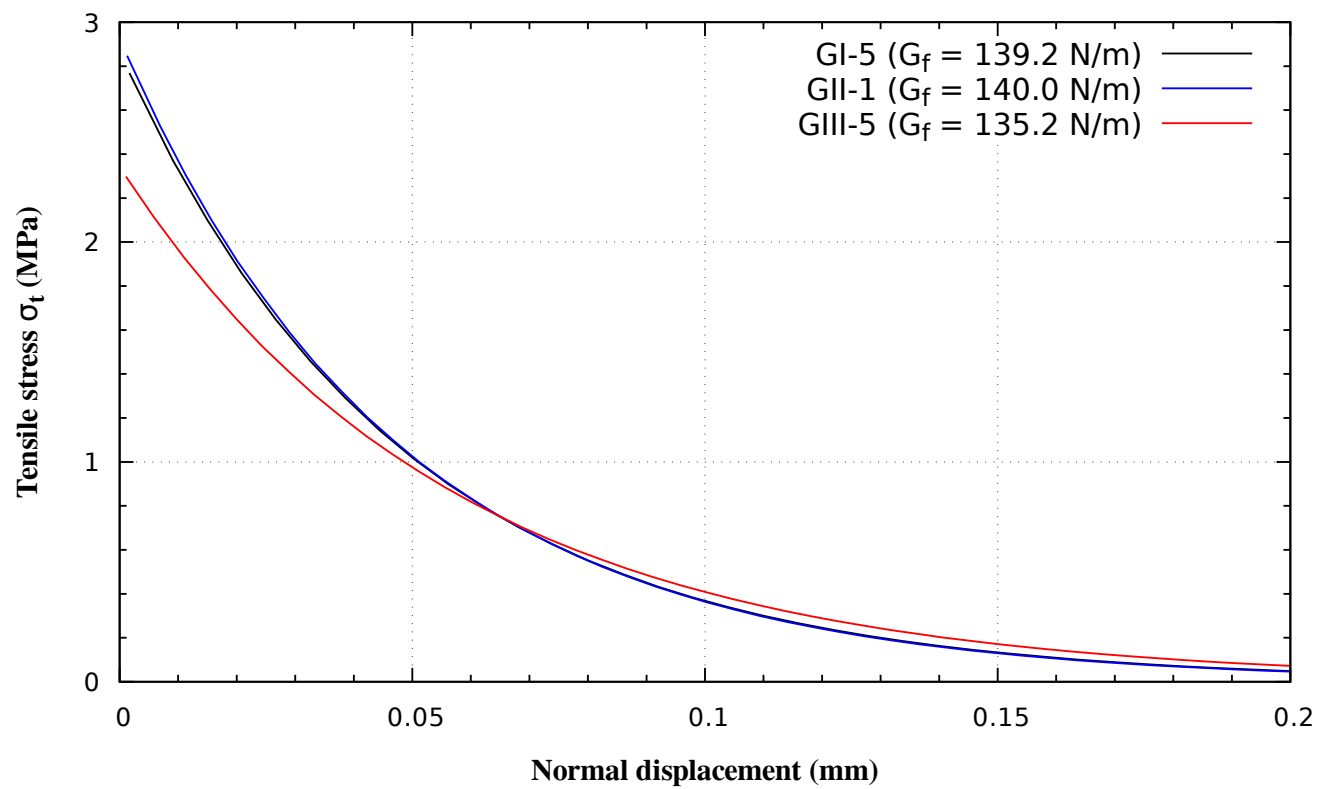

(b)

Figure 8: (a) Fitting of triaxial test data in meridian planes (after Ottosen [44]) and (b) uniaxial tension softening curves. 


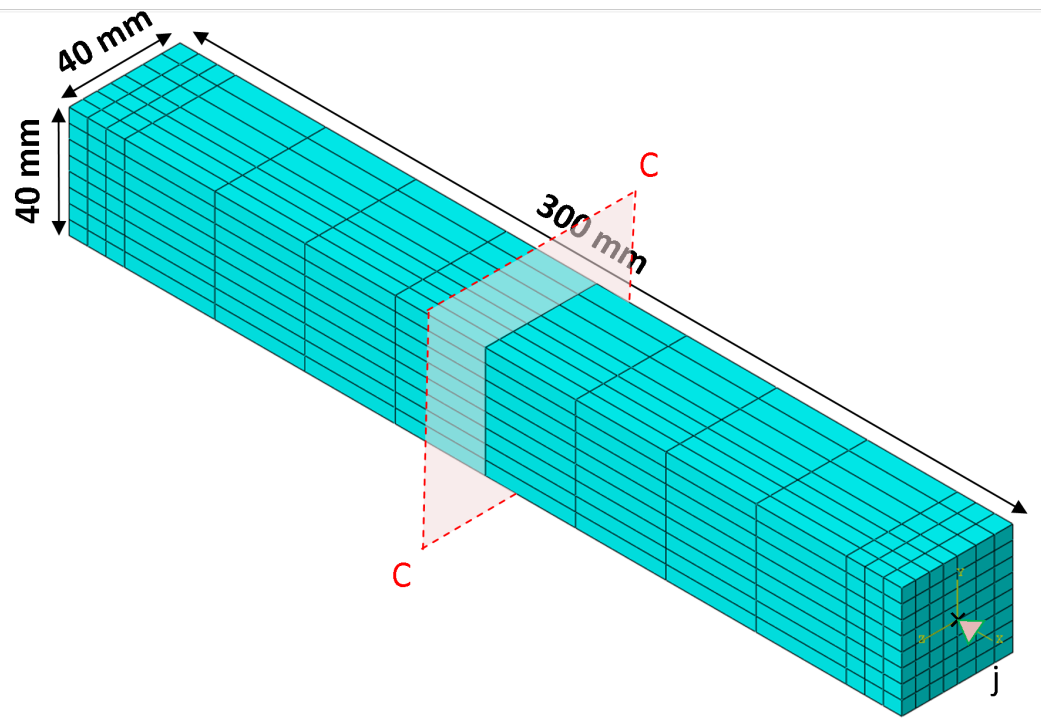

(a)

Boundary conditions at the exposed surfaces:

Relative humidity $h=55 \%$; Ambient temperature $T=23{ }^{\circ} \mathrm{C}$

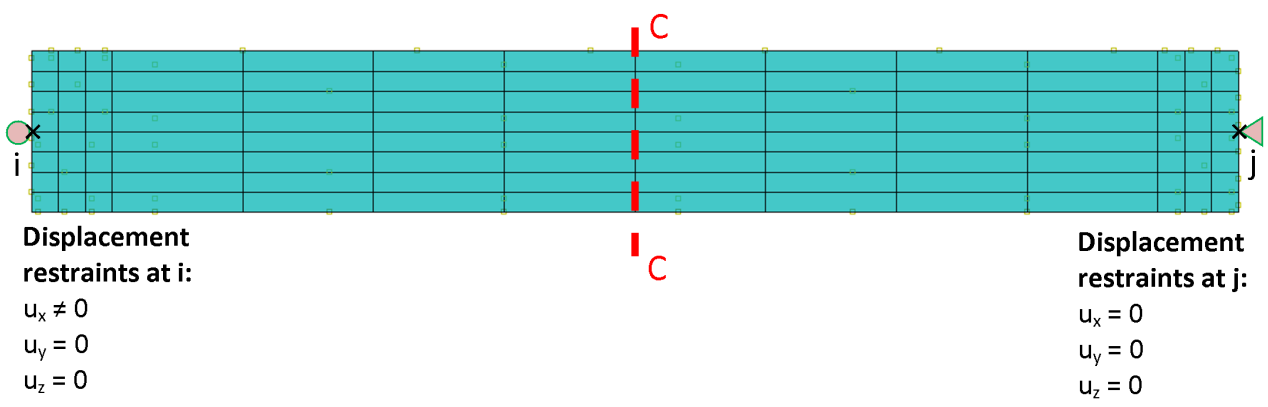

(b)

Figure 9: (a) Geometry and meshing of the prism model and (b) boundary conditions 


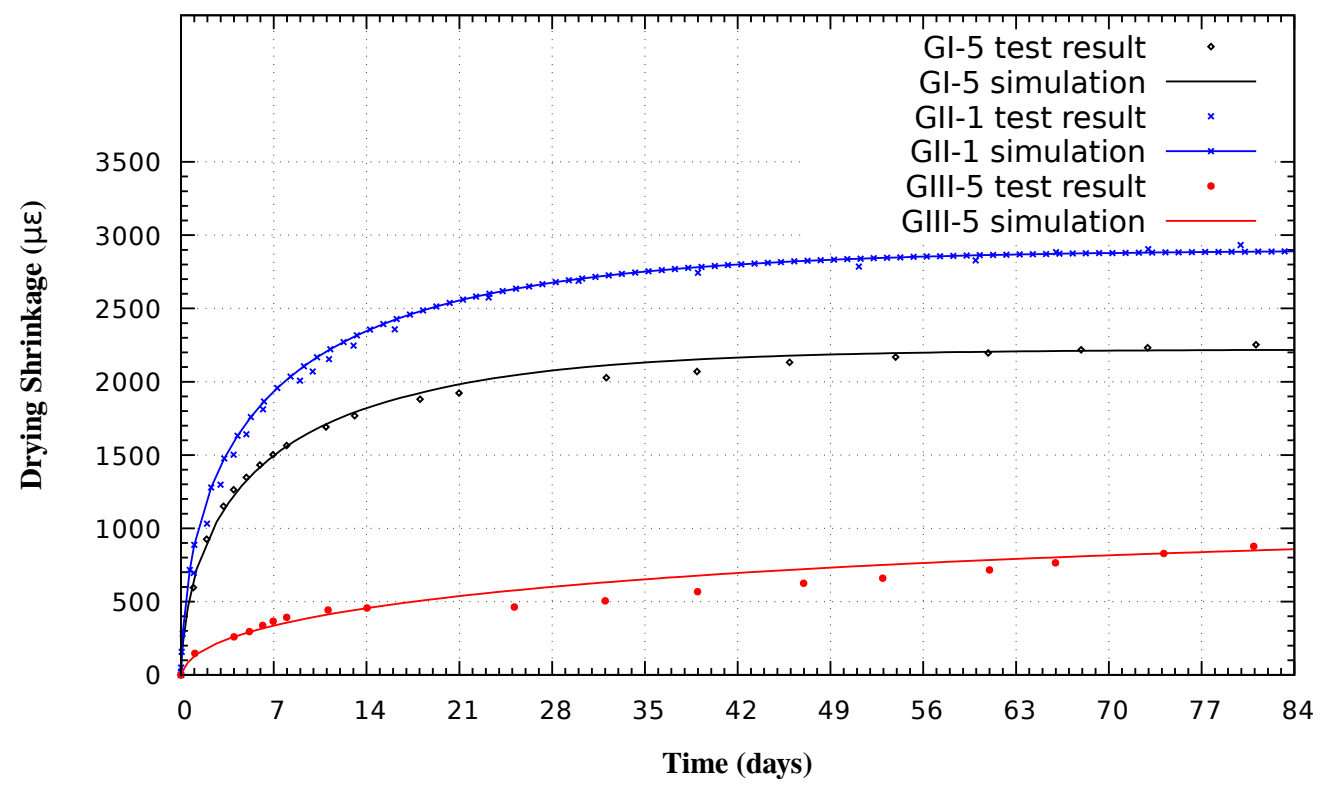

(a)

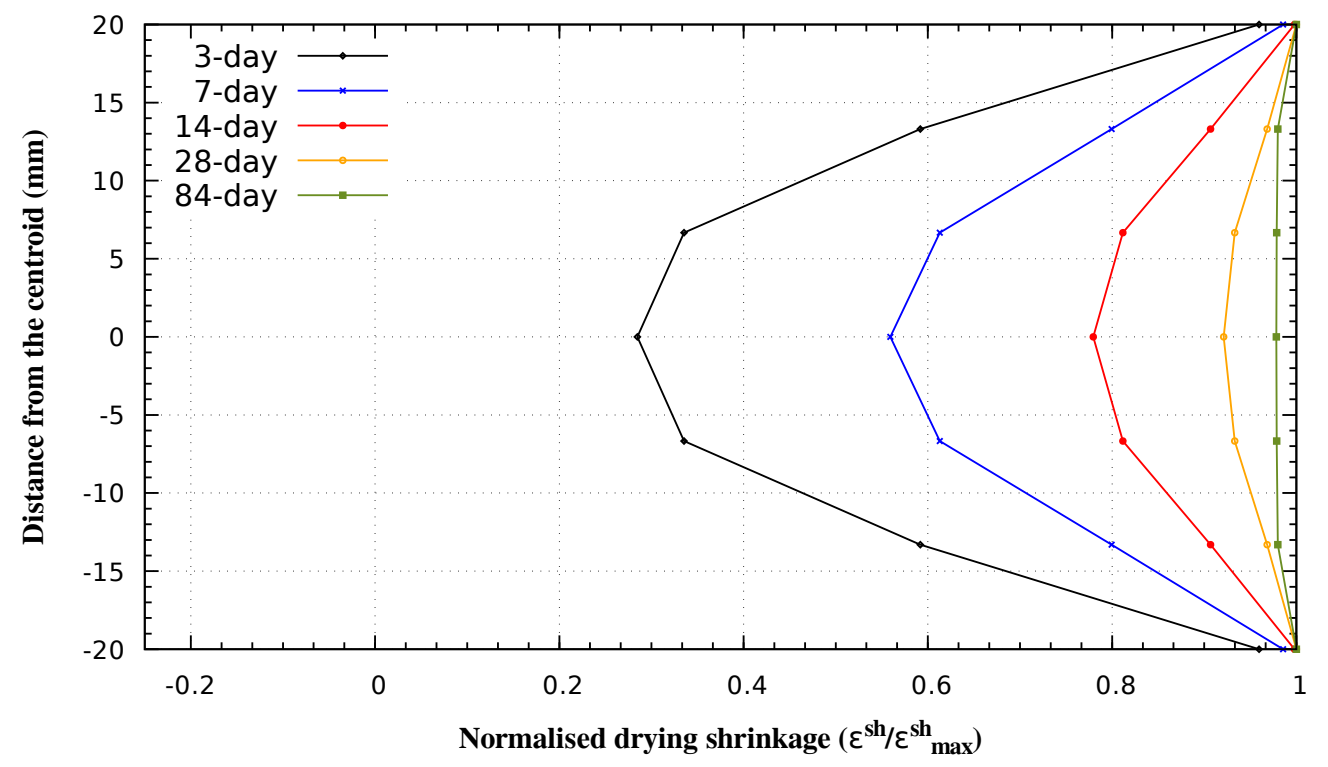

(b) 


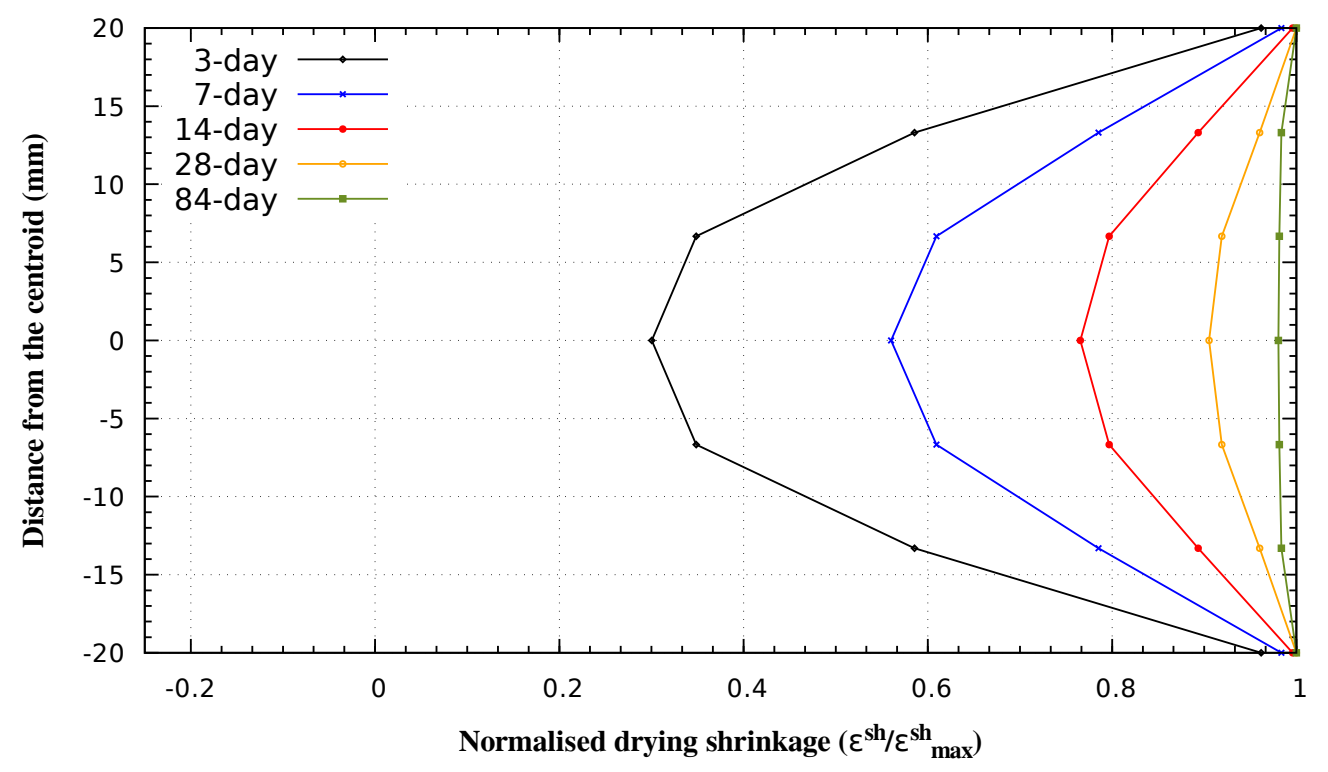

(c)

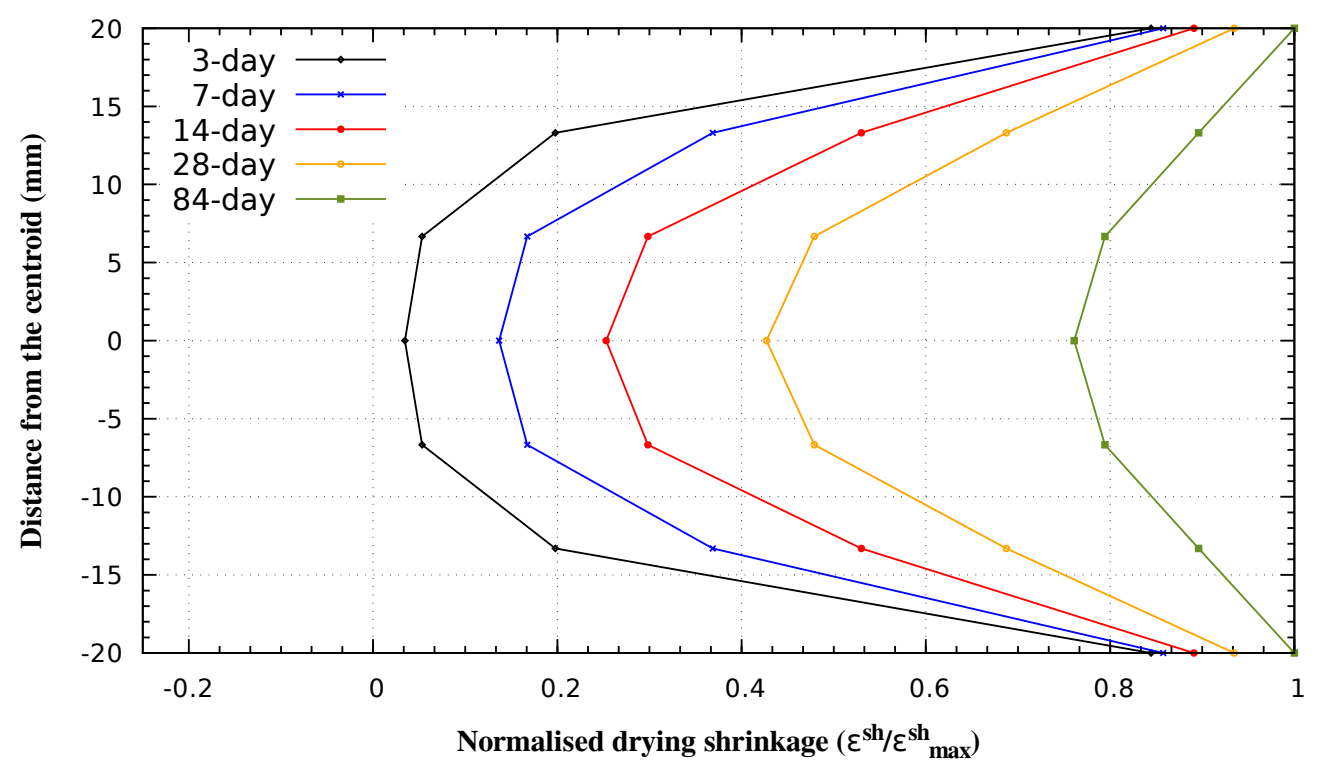

(d)

Figure 10: (a) Comparisons of the simulated with the tested drying-shrinkage curves, (b) cross-sectional (C-C) shrinkage distributions of GI-5, (c) cross-sectional (C-C) shrinkage distributions of GII-1, and (d) cross-sectional (C-C) shrinkage distributions of GIII-5 


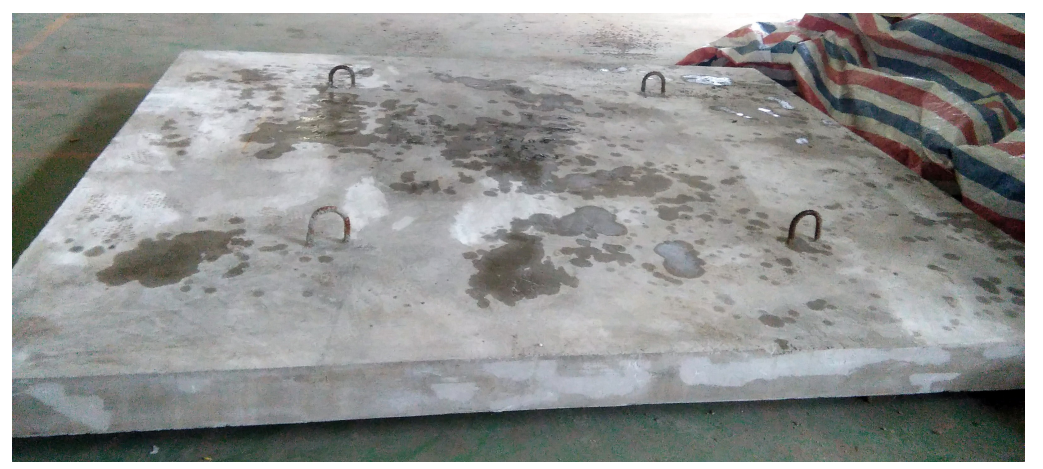

Figure 11: Photo of the reinforced foamed concrete slab in field test. 


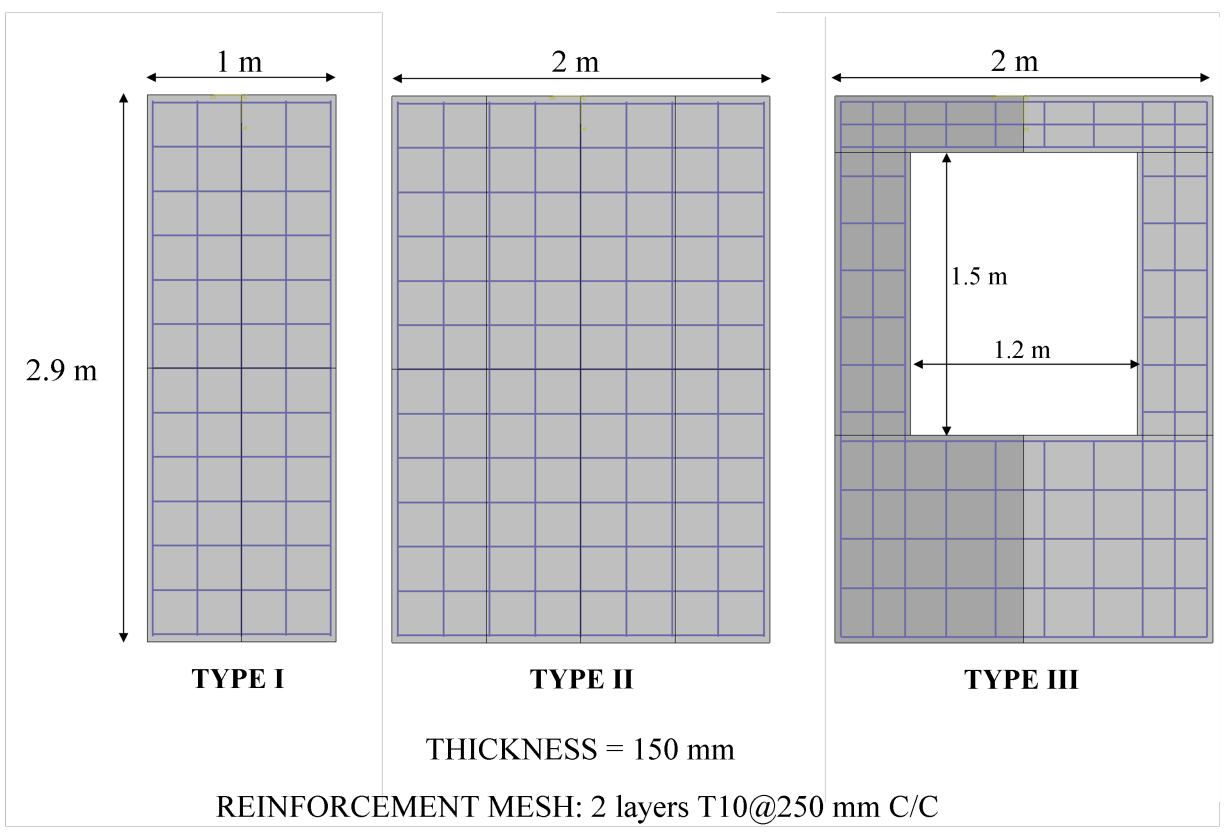

Figure 12: Prototypes of formworks. 

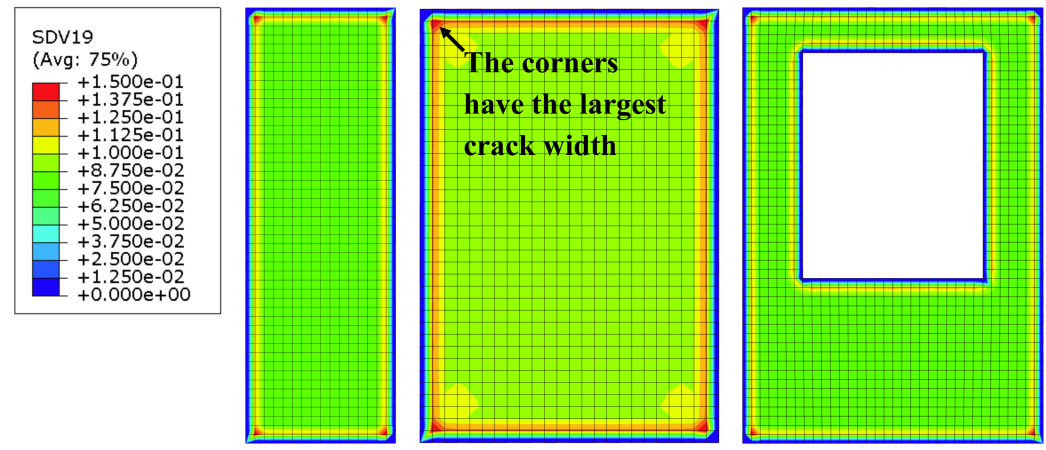

(a)
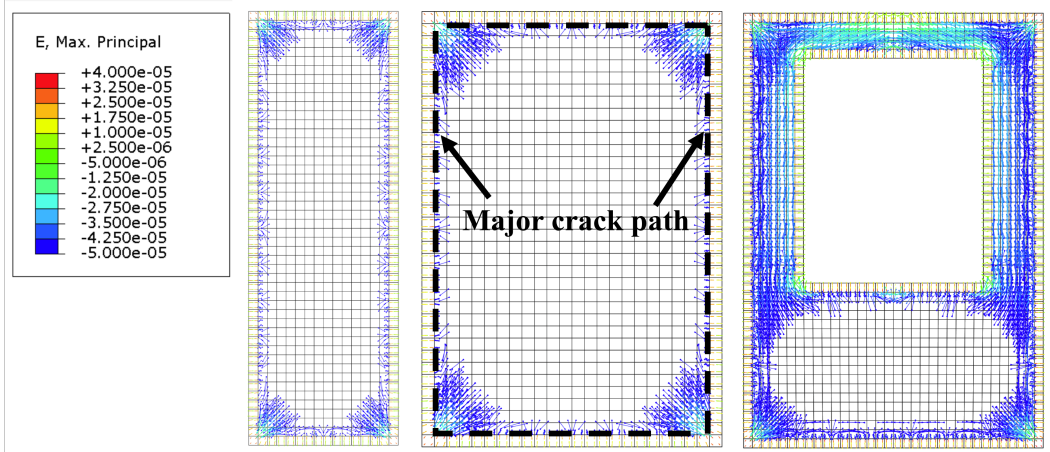

(b)
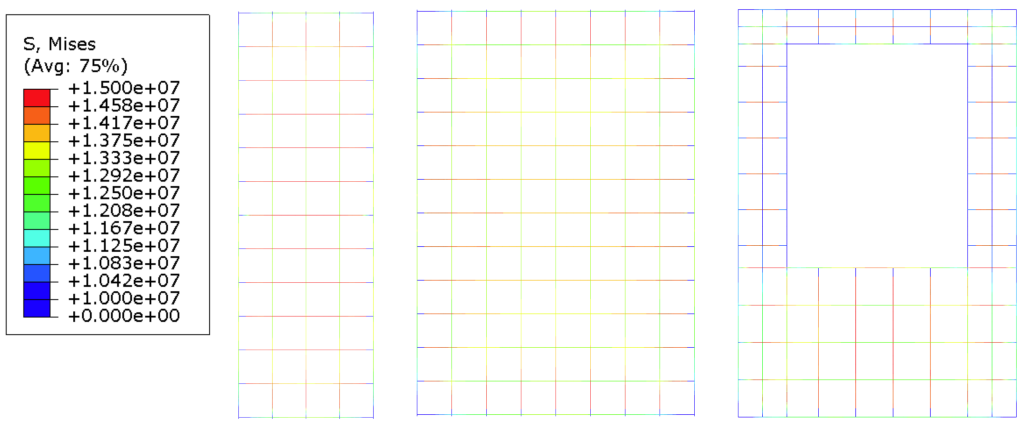

(c)

Figure 13: Simulated mechanical behaviour of GI-5 panel after 90 days: (a) equivalent crack width (state variable SDV 19 in $\mathrm{mm}$ ), (b) maximum principal strain direction, and (c) von Mises distribution in steel reinforcement mesh (in Pa). 


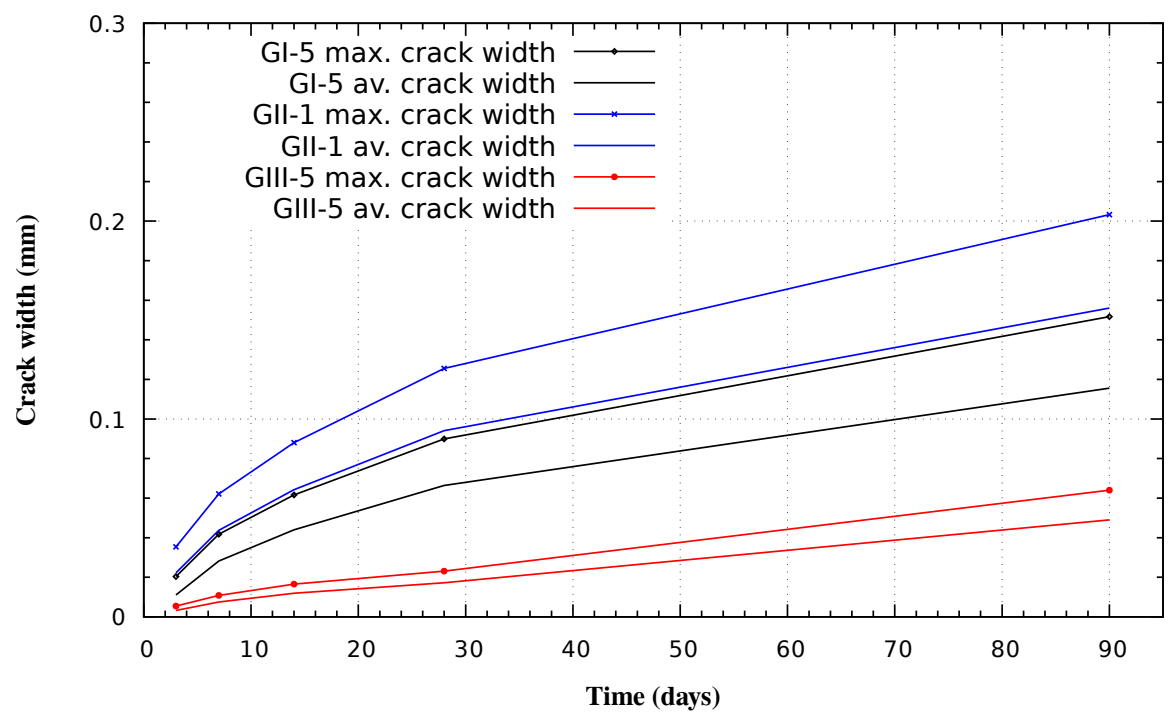

(a) Type I

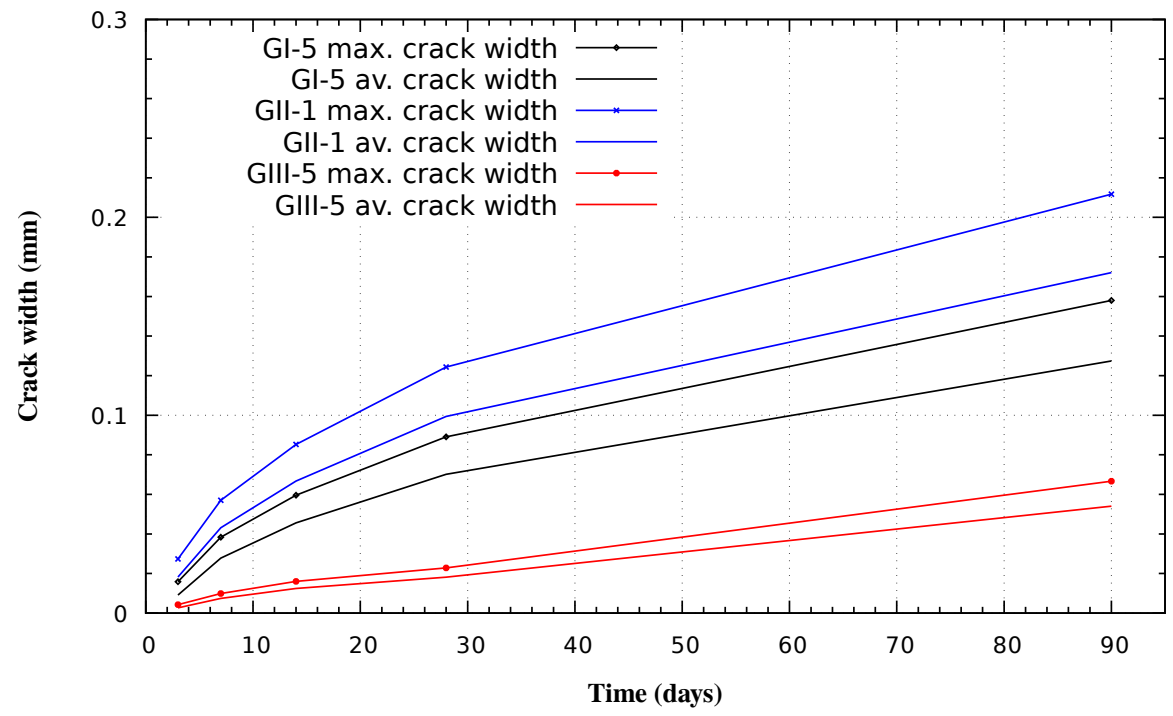

(b) Type II 


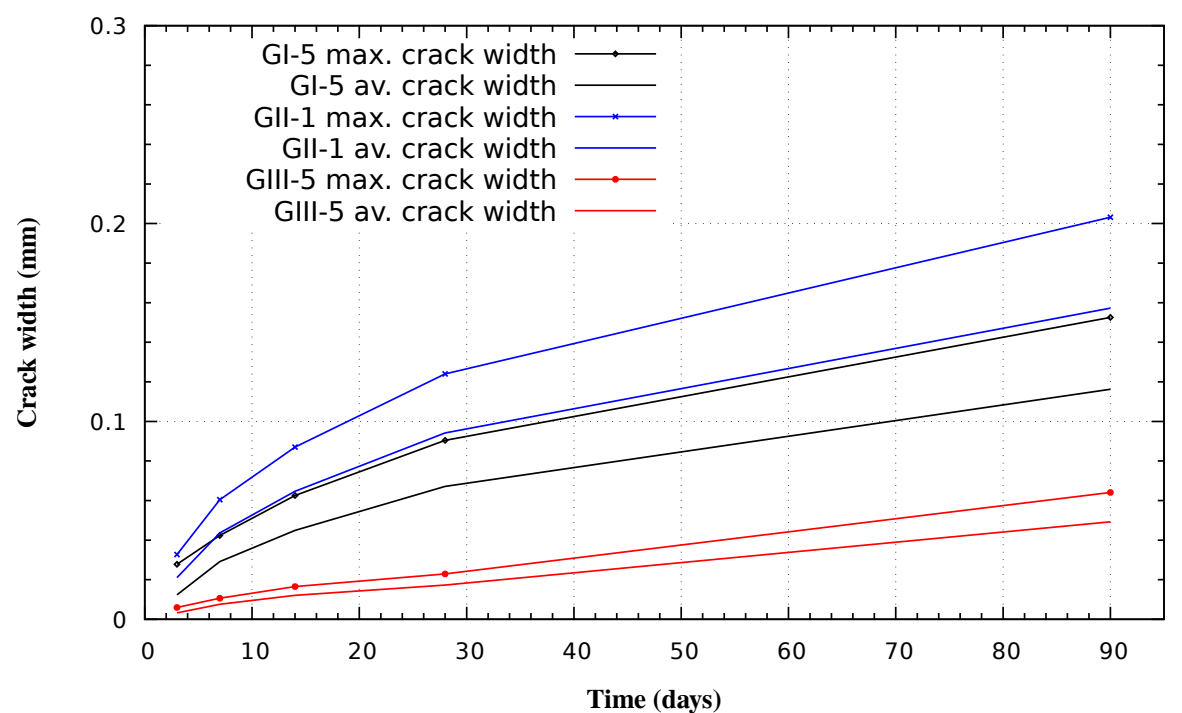

(c) Type III

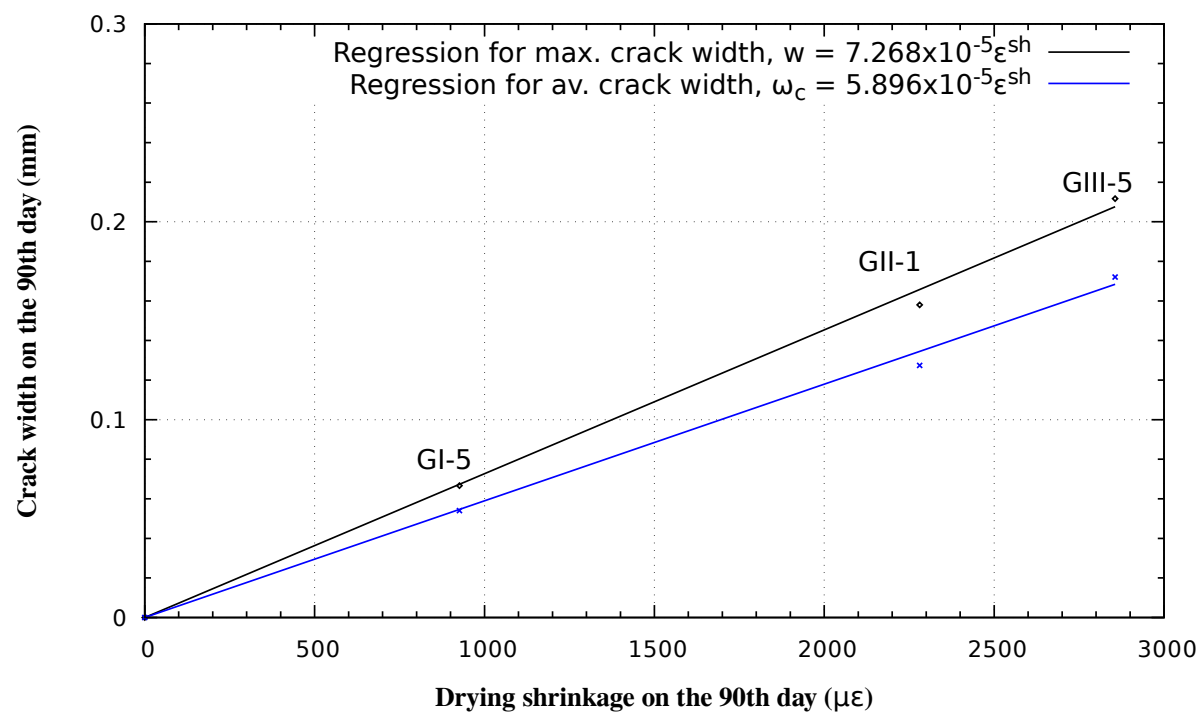

(d)

Figure 14: Maximum and average crack widths: (a) Type I formwork, (b) Type II formwork, (c) Type III formwork, and (d) regression relationships between free shrinkage and crack widths developed in Type II formwork at 90 days. 
Table 1: XRF elemental analysis of the raw materials.

\begin{tabular}{lccccc} 
& OPC & GGBS & $\begin{array}{c}\text { CSA } \\
\text { clinker }\end{array}$ & LF & SF \\
\hline $\mathrm{CaO}$ & $67.0 \%$ & $46.5 \%$ & $41.3 \%$ & $96.9 \%$ & $0.4 \%$ \\
$\mathrm{SiO}_{2}$ & $19.4 \%$ & $32.2 \%$ & $8.2 \%$ & $1.3 \%$ & $92.1 \%$ \\
$\mathrm{Al}_{2} \mathrm{O}_{3}$ & $3.4 \%$ & $12.3 \%$ & $32.9 \%$ & - & $4.6 \%$ \\
$\mathrm{MgO}$ & $1.0 \%$ & $4.1 \%$ & $2.8 \%$ & $1.8 \%$ & $0.5 \%$ \\
$\mathrm{Fe}_{2} \mathrm{O}_{3}$ & $3.5 \%$ & $1.0 \%$ & $1.6 \%$ & - & $1.0 \%$ \\
$\mathrm{SO}_{4}$ & $5.1 \%$ & $3.1 \%$ & $11.8 \%$ & - & $0.4 \%$
\end{tabular}


Table 2: Mix proportion of non-foamed mortar and foamed concrete.

\begin{tabular}{lllllllll} 
& OPC & GGBS & SF & LF & Water & FA & $\begin{array}{l}\text { Wet } \\
\text { density } \\
\left(\mathrm{kg} / \mathrm{m}^{3}\right)\end{array}$ & $\begin{array}{l}\text { Compressive } \\
\text { strength } \\
(\mathrm{MPa})\end{array}$ \\
\hline N1 & 0.667 & 0.333 & - & - & 0.285 & - & 2,000 & 94.3 \\
F1 & 0.667 & 0.333 & - & - & 0.285 & 0.0015 & 1,626 & 43.0 \\
\hline N2 & 0.230 & 0.740 & 0.03 & - & 0.285 & - & 2,061 & 90.5 \\
F2 & 0.230 & 0.740 & 0.03 & - & 0.285 & 0.0015 & 1,638 & 40.6 \\
\hline N3 & 0.184 & 0.592 & 0.024 & 0.2 & 0.285 & - & 2,060 & 90.0 \\
F3 & 0.184 & 0.592 & 0.024 & 0.2 & 0.285 & 0.0015 & 1,611 & 38.0 \\
FA = foaming agent & & & & & & \\
N = non-foamed & & & & & & & \\
F = foamed
\end{tabular}


Table 3: Mix proportion and compressive strength of non-foamed concrete.

\begin{tabular}{|c|c|c|c|c|c|c|c|c|c|c|c|}
\hline & $\mathrm{OPC}$ & GGBS & CSA-blend & SF & MEA & $\mathrm{LF}$ & Water & $\begin{array}{l}\text { SP } \\
(\%)\end{array}$ & $\begin{array}{l}\mathrm{BA} \\
(\%)\end{array}$ & $\begin{array}{c}\mathrm{HPMC} \\
(\%)\end{array}$ & $\begin{array}{l}\text { Compressiv } \\
\text { strength } \\
(\mathrm{MPa})\end{array}$ \\
\hline GI-1 & 0.97 & - & - & 0.03 & - & - & 0.285 & 0.125 & - & 0.005 & 105.2 \\
\hline GI-2 & - & 0.97 & - & 0.03 & - & - & 0.285 & 0.125 & - & 0.005 & 40.8 \\
\hline GI-3 & 0.5 & 0.47 & - & 0.03 & - & - & 0.285 & 0.125 & - & 0.005 & 96.0 \\
\hline GI-4 & 0.23 & 0.74 & - & 0.03 & - & - & 0.285 & 0.125 & - & 0.005 & 90.5 \\
\hline GI-5 & 0.77 & - & - & 0.03 & - & 0.2 & 0.285 & 0.125 & - & 0.005 & 90.1 \\
\hline GII-1 & 0.221 & 0.71 & - & 0.029 & $0.04^{1}$ & - & 0.285 & 0.125 & - & 0.005 & 93.1 \\
\hline GII-2 & 0.221 & 0.71 & - & 0.029 & $0.04^{2}$ & - & 0.285 & 0.125 & - & 0.005 & 99.1 \\
\hline GII-3 & 0.221 & 0.71 & - & 0.029 & $0.04^{3}$ & - & 0.285 & 0.125 & - & 0.005 & 101.4 \\
\hline GII-4 & 0.221 & 0.71 & - & 0.029 & $0.04^{4}$ & - & 0.285 & 0.125 & - & 0.005 & 103.3 \\
\hline GIII-1 & - & - & 0.97 & 0.03 & - & - & 0.28 & 0.125 & - & 0.005 & 91.7 \\
\hline GIII-2 & - & 0.74 & 0.23 & 0.03 & - & - & 0.30 & 0.125 & - & 0.005 & 35.2 \\
\hline GIII-3 & - & - & 0.77 & 0.03 & - & 0.2 & 0.3 & 0.125 & 0.21 & 0.005 & 72.5 \\
\hline GIII-4 & 0.115 & 0.54 & 0.115 & 0.03 & - & 0.2 & 0.27 & 0.125 & 0.50 & 0.005 & 59.0 \\
\hline GIII-5 & 0.115 & 0.425 & 0.23 & 0.03 & - & 0.2 & 0.28 & 0.125 & 0.75 & 0.005 & 76.8 \\
\hline GIII-6 & 0.115 & 0.225 & 0.23 & 0.03 & - & 0.4 & 0.28 & 0.125 & 0.75 & 0.005 & 48.0 \\
\hline
\end{tabular}

1: As-received MEA

2: Calcined the as-received MEA at $800^{\circ} \mathrm{C}$ for 1 hour

3: Calcined the as-received MEA at $900^{\circ} \mathrm{C}$ for 1 hour

4: Calcined the as-received MEA at $1,000^{\circ} \mathrm{C}$ for 1 hour

$\mathrm{SP}=$ superplasticiser (solid content)

$\mathrm{BA}=$ Boric acid

HPMC = Hydroxypropyl methylcellulose 
Table 4: The coefficients of best-fitted semi-log plot of drying shrinkage data and the expansive strain before shrinkage test.

\begin{tabular}{lcccl} 
Group & $a$ & $c$ & $\mathrm{R}^{2}$ & $\begin{array}{l}\text { Expansive } \\
\text { strain } \\
\text { before } \\
\text { shrinkage } \\
\text { test }(\mu \epsilon)\end{array}$ \\
& & & & \\
& & & & 23 \\
GI-1 & 347 & 1,987 & 0.991 & 233 \\
GI-2 & 605 & 2,355 & 0.978 & 133 \\
GI-3 & 466 & 2,439 & 0.984 & 175 \\
GI-4 & 521 & 2,846 & 0.973 & 179 \\
GI-5 & 339 & 1,960 & 0.981 & 103 \\
\hline GII-1 & 463 & 2,491 & 0.961 & 220 \\
GII-2 & 522 & 2,936 & 0.959 & 400 \\
GII-3 & 502 & 2,851 & 0.930 & 370 \\
GII-4 & 530 & 3,018 & 0.950 & 316 \\
\hline GIII-1 & 176 & 866 & 0.990 & 276 \\
GIII-2 & 154 & 650 & 0.962 & 260 \\
GIII-3 & 246 & 1,040 & 0.990 & 388 \\
GIII-4 & 207 & 905 & 0.948 & 98 \\
GIII-5 & 172 & 614 & 0.898 & 232 \\
GIII-6 & 290 & 1,269 & 0.951 & 164
\end{tabular}


Table 5: Calibrated elastoplastic parameters from drying shrinkage test.

\begin{tabular}{lccccccccccc} 
& $\begin{array}{c}f_{c, 28} \\
(\mathrm{MPa})\end{array}$ & $\begin{array}{c}E_{c, 28} \\
(\mathrm{MPa})\end{array}$ & $\nu$ & $k_{t}$ & $\begin{array}{c}G_{f} \\
(\mathrm{~N} / \mathrm{m})\end{array}$ & $\alpha_{p}$ & $\beta_{p}$ & $c_{p}$ & $d_{p}$ & $\varepsilon$ & $\begin{array}{c}\Psi \\
\text { (degree) }\end{array}$ \\
\hline GI-5 & 36.0 & 32963.5 & 0.2 & 0.0768 & 139.2 & 1.6881 & 4.2545 & 15.115 & 0.9913 & 0.1 & 15 \\
GII-1 & 37.2 & 33325.4 & 0.2 & 0.0765 & 140.0 & 1.6999 & 4.2769 & 15.185 & 0.9915 & 0.1 & 15 \\
GIII-5 & 29.2 & 31254.5 & 0.2 & 0.0787 & 135.2 & 1.6303 & 4.1441 & 14.773 & 0.9904 & 0.1 & 15
\end{tabular}


Table 6: Calibrated parameters for the drying shrinkage model

\begin{tabular}{lcccccccc} 
& $\begin{array}{c}b \\
(\mathrm{MPa})\end{array}$ & $K_{s, 28}$ & $\alpha_{H}$ & $\begin{array}{c}D_{1}(h=1) \\
\left(\mathrm{mm}^{2} / \text { day }\right)\end{array}$ & $\begin{array}{c}D_{0}(h=0) \\
\left(\mathrm{mm}^{2} / \text { day }\right)\end{array}$ & $\alpha_{D}$ & $\beta$ & $\begin{array}{c}k_{H} \\
(\mathrm{~mm} / \text { day })\end{array}$ \\
\hline GI-5 & 0.75 & 73962.3 & 1.25 & 12.8259 & 0.5772 & 22.22 & 3.8 & 5 \\
GII-1 & 0.90 & 185140.9 & 1.36 & 14.5681 & 0.5099 & 28.57 & 3.8 & 5 \\
GIII-5 & 0.48 & 33073.52 & 1.10 & 2.0463 & 0.0614 & 33.33 & 3.8 & 5
\end{tabular}


Table 7: Summary of the measurement of drying shrinkage in the field trial after 193 days.

\begin{tabular}{lc} 
Sample & $\begin{array}{c}\text { Drying shrinkage } \\
(\mu \varepsilon)\end{array}$ \\
\hline Foamed GIII-5 & 161 \\
$90 \%$ OPC $+10 \% C \bar{S}$ & 2,546 \\
$90 \%$ OPC $+10 \% C \bar{S} H_{2}$ & 1,843 \\
$90 \%$ OPC $+5 \% C \bar{S}+5 \% C \bar{S} H_{2}$ & 2,733
\end{tabular}

